\title{
Inter-regional Competition, Comparative Advantage, and Environmental Federalism
}

\author{
Ida Ferrara*, Paul Missios ${ }^{\dagger}$ and Halis Murat Yildiz ${ }^{\ddagger}$
}

October 21, 2010

\begin{abstract}
In this paper, we compare endogenous environmental policy setting with centralized and decentralized governments when regions have comparative advantages in different polluting goods. We develop a tworegion, two-good model with inter-regional environmental damages and perfect competition in product markets, where both regions produce both goods. Despite positive spillovers of pollution across regions, the model predicts that decentralization may lead to weaker or stricter environmental standards or taxes, depending on the degree of regional comparative advantage and the extent of transboundary pollution. This suggests that federalism can lead to either a "race to the bottom" or a "race to the top," without relying on inefficient lobbying efforts or capital competition.
\end{abstract}

Keywords: Environmental policy, Federalism, Centralism.

JEL Classifications: H77, Q56, H41

\footnotetext{
*York University, 4700 Keele Street, North York, Ontario, Canada M3J1P3. E-mail: iferrara@yorku.ca.

${ }^{\dagger}$ Ryerson University, 350 Victoria Street, Toronto, ON, Canada M5B 2K3. E-mail: pmissios@ryerson.ca.

${ }^{\ddagger}$ Ryerson University, 350 Victoria Street, Toronto, ON, Canada M5B 2K3. E-mail: hyildiz@ryerson.ca.
} 


\section{Introduction}

Critical to the setting of domestic environmental policy is whether a centralized government would select more or less stringent regulations than decentralized governments. Earlier literature has suggested that decentralization can lead to a "race to the bottom," as state, provincial, or regional governments over-compete for domestic firms and/or capital (e.g., Markusen et al., 1995; Richter and Wellisch, 1996; Levinson, 1997; Kunce and Shogren, 2002, 2005; McAusland, 2002) or cause firms to over-invest in unproductive lobbying activities (e.g., Aidt, 1998; Fredriksson et al., 2006), but may alternatively lead to no difference in policy outcomes (e.g., Oates and Schwab, 1988; Fredricksson and Gaston, 2000) or to improvements in environmental quality through better information about local impacts, the internalization of transboundary pollution spillovers, or the capture of pollution rents by non-local capital owners (e.g., Peltzman and Tideman, 1972; Wellisch, 1995). The results in relation to environmental policy mirror those of the local public finance or fiscal federalism literature, where decentralization can serve as a disciplinary measure against expansionary government taxation or can push governments to efficient public good provision through the ability of individuals to relocate, but may alternately result in excessive tax competition to attract firms, employment, and/or capital (Oates and Schwab, 1988). Parallel to this, the main focus of the environmental policy literature has been on the locational decision of firms, with governments playing the role as active seekers of employment and capital in environmental policy setting.

Empirical evidence on the impact of environmental policy decentralization has been mixed, although there is a consensus that decentralization does not necessarily lead to a "race to the bottom" as much as the theoretical literature suggests. For example, List and Gerking (2000), using data from before and after the Reagan decentralization of environmental policy enforcement in the early 1980s, found that real pollution-abatement operating expenditures per $\$ 1000$ of value-added increased for two of the four industries considered (chemical/allied products and food/kindred products) but declined in the other two sectors (primary metals and chemical/applied products). Quite consistent with this, Millimet (2003) found that environmental decentralization in the U.S. in the 1980s led to a significant increase in pollution control expenditure, but per capita nitrogen oxide and sulfur dioxide emissions did not significantly decrease (although there may have been a reduction in the rate of deterioration). More on environmental policy than environmental outcomes, Sigman (2005) has suggested that free riding by state governments does occur in water pollution control and, specifically, that states which control their Clean Water Act programs free ride on downstream states, implying that centralization may be warranted if the cost of free-riding outweighs the greater flexibility and informational advantages of decentralization. 
A perusal of recent environmental indicators from the World Bank, across different pollutants and among different countries, illustrates a similar ambiguity (see Table 1). For example, among the 30 OECD countries, the 9 countries generally identified as federations have average carbon dioxide emissions per capita of 11.4 metric tonnes and nationally protected area (as a share of total land area) of $15.7 \%,{ }^{1}$ while the countries identified as having centralized governments have lower average carbon dioxide emissions per capita (9.2 metric tonnes) but a lower average percentage of nationally protected area (12.8\%). In terms of outcomes, centralized regimes thus have better carbon emissions per capita but protect less of their land area. Fertilizer consumption (hundred grams per hectare of arable land) is also very much lower among federations (1341 to 3627), but particulate matter emissions (urban-population-weighted average, $\mu \mathrm{g} / \mathrm{m}^{3}$ ) are virtually identical (25.7 to 25.2 ). This inconsistency occurs across pollutants for non-OECD countries as well. It appears, at least on the surface, that decentralization does not even lead to consistent environmental outcomes within a country: some pollutants may by higher with decentralization while others are lower.

In this paper, we revisit the theoretical question about the environmental implications of policy decentralization, focusing on the role of productivity gaps and pollution spillovers, in an attempt to provide a plausible explanation for the observed policy inconsistency. Specifically, we address the following questions: (1) How does comparative advantage across regions affect environmental policy and damages? (2) What are the differences in the patterns of environmental policy between centralism and federalism when regions are relatively better at producing different polluting goods? (3) How does harmonization of centralized policy impact the environment? (4) With multiple goods and multiple pollutants (and therefore potentially multiple taxes), how do environmental damages differ between federalism and centralism?

We use a model comprising a single country with two regions, two (non-numeraire) goods produced by perfectly competitive industries and a numeraire good. Each region produces both non-numeraire goods but has a comparative advantage in one of them. The numeraire good is assumed to be non-polluting and freely traded while the two non-numeraire goods generate different pollutants, which may be transboundary, and are thus subject to environmental taxes. We consider a two-stage game under two government structures: federalism (or decentralization) and centralism. In the first stage, either the centralized government sets environmental taxes to levy on the two polluting goods in each region to maximize national welfare (under centralism), or each of the two regional governments sets its own taxes to maximize regional welfare (under

\footnotetext{
${ }^{1}$ Countries are separated by overall government structure, which may not always be consistent with that of environmental policy. The countries categorized as federations are Austria, Australia, Belgium, Canada, Germany, Mexico, Spain, Switzerland, and the United States of America.
} 
federalism). Under the centralized policy regime, we also consider the case in which the central government chooses to harmonize taxes within each sector between the two regions. In the second stage of the game, given the environmental taxes and the structure of government (centralism versus federalism), production, inter-regional transfers of goods across regions, and consumption take place. In the discussion of the differences in taxes and damages between regimes, we describe three distinct effects: an inter-regional environmental effect from cross-border pollution spillovers which tends to push up taxes, an intra-regional environmental effect between sectors within a region which has an ambiguous impact on taxes, and an inter-regional trade effect from consumption in which tends to lower taxes.

\begin{tabular}{|c|c|c|c|c|}
\hline Country & Nationally Protected Area & $\mathrm{CO} 2$ Emissions Per Capita & Fertilizer Consumption & Particulate Matter \\
\hline \multicolumn{5}{|l|}{ Federal } \\
\hline Austria & 28.5 & 8.5 & 2332 & 15 \\
\hline A ustalia & 9.7 & 16.2 & 448 & 34 \\
\hline Belgium & 3.5 & 9.7 & .. & 23 \\
\hline Canada & 6.9 & 20.0 & 692 & 19 \\
\hline Germany & 32.0 & 9.8 & 2122 & 19 \\
\hline Mexico & 5.1 & 4.3 & 692 & 40 \\
\hline Spain & 9.3 & 7.7 & 1286 & 34 \\
\hline Switzerland & 29.6 & 5.5 & 2230 & 25 \\
\hline USA & 16.3 & 20.6 & 1005 & 22 \\
\hline \multicolumn{5}{|l|}{ Centralized } \\
\hline Czech Republic & 18.7 & 11.5 & 1525 & 22 \\
\hline Denmark & 25.7 & 9.8 & 599 & 19 \\
\hline Finland & 9.7 & 12.6 & 1344 & 18 \\
\hline France & 3.0 & 6.2 & 2032 & 14 \\
\hline Greece & 3.3 & 8.7 & 1652 & 36 \\
\hline Hungary & 9.3 & 5.7 & 1234 & 18 \\
\hline Iceland & 4.7 & 7.6 & 25249 & 17 \\
\hline Ireland & 1.1 & 10.4 & 4619 & 17 \\
\hline Italy & 11.0 & 7.7 & 1569 & 28 \\
\hline Japan & 14.3 & 9.8 & 3908 & 31 \\
\hline Luxembourg & 17.0 & 24.9 & 4907 & 15 \\
\hline Netherlands & 28.0 & 8.7 & 6231 & 35 \\
\hline New Zealand & 24.2 & 7.7 & 7026 & 15 \\
\hline Norway & 6.5 & 19.1 & 1909 & 20 \\
\hline Poland & 9.7 & 8.0 & 1281 & 37 \\
\hline Portugal & 5.1 & 5.6 & 1709 & 28 \\
\hline Slovak Republic & 22.8 & 6.7 & 1125 & 16 \\
\hline South Korea & 2.6 & 3.4 & .. & 12 \\
\hline Sweden & 10.9 & 5.9 & 889 & 43 \\
\hline United Kingdom & 25.0 & 9.8 & 2898 & 16 \\
\hline All Federal Countries (mean) & 15.7 & 11.4 & 1341 & 25.7 \\
\hline All Centralized Countries (mean) & 12.8 & 9.2 & 3627 & 25.2 \\
\hline
\end{tabular}

Table 1. Environmental performance indicators for the 30 OECD countries, separated into federations and centralized groups. Source: World Bank (2008). 


\section{The Model}

We consider a country with two regions $(A$ and $B)$ and three goods (a numeraire good and two nonnumeraire goods which we label $a$ and $b$ ). Region $A$ has a comparative advantage in the production of $a$ while region $B$ has a comparative advantage in the production of $b$. We assume perfect competition in all markets but allow for the production of each of the two non-numeraire goods to generate pollution which may have transboundary effects. The presence of pollution calls for policy intervention and we consider non-prohibitive environmental taxes $(t)$ that could be imposed on producers either by the central government or by the local government.

On the demand side, we have quasi-linear preferences represented by

$$
u\left(\mathbf{c}, c_{0}\right)=v(\mathbf{c})+c_{0}
$$

where $\mathbf{c}=\left[c_{a}, c_{b}\right]$ is the consumption vector for the two non-numeraire goods, $c_{0}$ denotes the consumption of the numeraire good, and $v(\mathbf{c})$ is quadratic and additively separable in the non-numeraire goods. The demand for good $i(i=a, b)$ in region $j(j=A, B)$ is then given by

$$
d\left(p_{i}^{j}\right)=\alpha-p_{i}^{j}
$$

On the supply side, as in Horn et al. (2007), labour $(l)$ is the only factor of production which is employed in the production of the numeraire good according to a constant-returns-to-scale technology and in the production of each of the two non-numeraire goods according to a decreasing-returns-to scale technology.

Specifically, non-numeraire good $i$ is produced in region $j$ according to $x_{i}^{j}=\sqrt{2 \lambda_{i}^{j}} l$, where $\lambda_{i}^{j} \in(0,1]$ with $\lambda_{i}^{j}=1$ if region $j$ has a comparative advantage in the production of good $i$ and with $\lambda_{i}^{j}<1$ otherwise. If the marginal product of labour in the production of the numeraire good is one and the supply of labour is sufficiently large that production is positive at all times, we have that the equilibrium wage is equal to one and the total supply of non-numeraire good $i$ is equal to

$$
x_{i}^{j}=\lambda_{i}^{j}\left(p_{i}^{j}-t_{i}^{j}\right) \text {, }
$$

where $t_{i}^{j}$ denotes the environmental tax producers of good $i$ face in region $j$.

Assuming that (1) each unit of production generates one unit of pollution, (2) pollution may be transboundary, (3) each production process entails a different pollutant, and (4) environmental damages are separable in pollutants and quadratic in their levels, we can write the environmental damage function in region $j$ as

$$
\psi^{j}=\left(\frac{x_{a}^{j}+s_{a} x_{a}^{-j}}{2}\right)^{2}+\left(\frac{x_{b}^{j}+s_{b} x_{b}^{-j}}{2}\right)^{2},
$$


for $j=A, B$, where $s \in[0,1]$ and measures the extent to which pollution generated in the other $(-j)$ region travels to region $j$ so that the higher the $s$, the more transboundary pollution is. As we have two polluting production processes and thus two pollutants, we can allow for the transboundary nature of the two pollutants to differ by indexing $s$ with the subscript $i(i=a, b)$.

Our framework of analysis involves two stages: in the first stage, environmental taxes are set to maximize welfare defined as the sum of consumer surplus, producer surplus, and tax revenues minus environmental damage; in the second stage, consumption and production decisions take place under the assumption that markets are perfectly competitive. For the first stage, we consider two scenarios: in one case, policy is set centrally so that the objective function includes both the welfare of region $A$ and the welfare of region $B$; in the other case, policy is set locally at the regional level so that the objective function includes only the welfare of the region in which environmental policy is being introduced.

\subsection{Consumption and Production Stage}

In this subsection, we look at the second stage of the model and solve for equilibrium prices and quantities for given environmental taxes. Under zero transportation costs, $p_{i}^{A}=p_{i}^{B}$, that is, the price consumers pay for good $i$ is the same independently of where it is produced, and we can thus omit the superscript $j$ and express the price of good $i$ simply as $p_{i}$. Market clearing then requires that national demand equal national supply or

$$
2\left(\alpha-p_{i}\right)=\left(\lambda_{i}^{A}+\lambda_{i}^{B}\right) p_{i}-\lambda_{i}^{A} t_{i}^{A}-\lambda_{i}^{B} t_{i}^{B}
$$

which gives

$$
p_{i}=\frac{2 \alpha+\lambda_{i}^{A} t_{i}^{A}+\lambda_{i}^{B} t_{i}^{B}}{2+\lambda_{i}^{A}+\lambda_{i}^{B}}
$$

for $i=a, b$. Using that $\lambda_{a}^{A}=\lambda_{b}^{B}=1$, we can express equilibrium price, production, and export levels as

$$
\begin{gathered}
p_{i}=\frac{2 \alpha+t_{i}^{j}+\lambda_{i}^{-j} t_{i}^{-j}}{3+\lambda_{i}^{-j}} \\
x_{i}^{j}=\frac{2 \alpha+t_{i}^{-j} \lambda_{i}^{-j}-t_{i}^{j}\left(2+\lambda_{i}^{-j}\right)}{3+\lambda_{i}^{-j}} \text { and } x_{i}^{-j}=\frac{\lambda_{i}^{-j}\left(2 \alpha+t_{i}^{j}-3 t_{i}^{-j}\right)}{3+\lambda_{i}^{-j}},
\end{gathered}
$$

and

$$
x_{i}^{j}-d\left(p_{i}\right) \equiv d\left(p_{i}\right)-x_{i}^{-j}=\frac{\alpha\left(1-\lambda_{i}^{-j}\right)-t_{i}^{j}\left(1+\lambda_{i}^{-j}\right)+2 \lambda_{i}^{-j} t_{i}^{-j}}{3+\lambda_{i}^{-j}},
$$

respectively, for $j=A$ (so that $-j=B$ ) when $i=a$ and $j=B$ (so that $-j=A$ ) when $i=b$, which is a labeling strategy we adopt throughout the paper. 
Here we note that the environmental tax in the region with a comparative advantage has a stronger price effect than the environmental tax in the other region. That is, the tax imposed on producers of good $a$ in region $A$, for example, affects the price of good $a$ to a greater extent than the tax on producers of good $a$ in region $B$. Furthermore, an environmental tax reduces production in the region in which it is levied but increases it in the other region, although the latter effect is weaker (in absolute terms) than the former effect. Finally, inter-regional exports are decreasing in the environmental tax imposed in the exporting region but increasing in the environmental tax imposed in the importing region, although again the dependence is weaker in the latter than in the former. For example, the tax on producers of good $a$ in region $A$ reduces exports of good $a$ from region $A$ to region $B$ but the tax on producers of good $a$ in region $B$ increases exports of good $a$ from region $A$ to region $B$.

Given environmental taxes, the effects of an increase in $\lambda$, which amounts to a reduction in comparative advantage, are less straightforward but equally unambiguous. By partial differentiation of the above equilibrium price and quantity levels, we have that

$$
\begin{gathered}
\frac{\partial p_{i}}{\partial \lambda_{i}^{-j}}=-\frac{x_{i}^{-j}}{\lambda_{i}^{-j}\left(3+\lambda_{i}^{-j}\right)}<0 \\
\frac{\partial x_{i}^{j}}{\partial \lambda_{i}^{-j}}=-\frac{x_{i}^{-j}}{\lambda_{i}^{-j}\left(3+\lambda_{i}^{-j}\right)}<0 \text { and } \frac{\partial x_{i}^{-j}}{\partial \lambda_{i}^{-j}}=\frac{3 x_{i}^{-j}}{\lambda_{i}^{-j}\left(3+\lambda_{i}^{-j}\right)}>0
\end{gathered}
$$

and

$$
\frac{\partial\left[x_{i}^{j}-d\left(p_{i}\right)\right]}{\partial \lambda_{i}^{-j}}=-\frac{2 x_{i}^{-j}}{\lambda_{i}^{-j}\left(3+\lambda_{i}^{-j}\right)}<0 .
$$

As $\lambda$ increases, prices and exports decline while production decreases in the region with the comparative advantage but increases in the other region. Overall, production in sector $i$ increases as the production increase in the less efficient region is larger than the production decrease in the more efficient region.

\subsection{Environmental Policy Stage}

In this subsection, we examine the environmental policy setting stage and consider two scenarios: first, we have the central government determine the environmental taxes to levy in the two polluting sectors ( $a$ and $b$ ) in each of the two regions $(A$ and $B)$; second, we allow for each regional government to choose the environmental taxes to impose in the two sectors. Although in both cases environmental taxes are welfaremaximizing, there are two channels through which environmental policy in one region affects the other region (trade and pollution movement) giving rise to effects that are only taken into account by the central government and thus amount to different environmental taxes between federalism and centralism. Trade 
between regions connects consumers and producers in one region with the policy choice in the other region generating an inter-regional trade effect that is increasing in the level of trade activity and thus in the productivity gap between the two regions (the lower the gap is, the lower the level of trade activity and the weaker the effect). Given the trade possibilities across the two regions, there also exists substitutability in production across the two regions through environmental policy. Specifically, environmental taxes reduce local production but increase production in the other region, and a change in production has both an environmental effect through a change in emissions and a tax revenue effect through a change in tax revenues. The second channel through which environmental policy in a region affects the other region is pollution movement which generates an environmental effect that is increasing in how transboundary pollution is (the more transboundary pollution is, the stronger the effect).

To sum up, there are three effects explaining any policy divergence between centralism and federalism: an inter-regional trade effect, which depends on the extent of trade, an inter-regional environmental effect which captures how a tax increase in a region affects pollution in the other region and depends on substitutability in production between the two regions as well as on the transboundary nature of pollution, and a tax revenue effect which depends on substitutability in production between the two regions.

In technical terms, the effects of $t_{i}^{j}$ in region $-j$ which a central government takes into account but a regional government does not can be expressed as

$$
\underbrace{\left[x_{i}^{-j}-d\left(p_{i}\right)\right] \frac{\partial p_{i}}{\partial t_{i}^{j}}}_{\text {trade effect }}+\underbrace{[\underbrace{\left(\frac{x_{i}^{-j}+s_{i} x_{i}^{j}}{2}\right) \frac{\partial x_{i}^{-j}}{\partial t_{i}^{j}}}_{\text {own pollution effect }}+\underbrace{\left(\frac{x_{i}^{-j}+s_{i} x_{i}^{j}}{2}\right) s_{i} \frac{\partial x_{i}^{j}}{\partial t_{i}^{j}}}_{\text {spillover effect }}]}_{\text {inter-regional environmental effect }}+\underbrace{t_{i}^{-j} \frac{\partial x_{i}^{-j}}{\partial t_{i}^{j}}}_{\text {tax effect }}
$$

for $j=A, B$ and $i=a, b$. Provided that some level of trade activity is present, the inter-regional trade effect increases the marginal cost of environmental taxes in sectors in which regions have a comparative advantage and decreases it otherwise. To be clear, a higher tax in region $j$ reduces consumer surplus (through higher prices and lower consumption) and increases producer surplus (through higher prices and larger production) in region $-j$. If region $-j$ imports from region $j$, that is, $x_{i}^{-j}<d\left(p_{i}\right)$, the effect on consumer surplus prevails so that overall surplus decreases and the marginal cost of taxes increases. However, if region $-j$ exports to region $j$, that is, $x_{i}^{-j}>d\left(p_{i}\right)$, the effect on producer surplus prevails so that overall surplus increases and the marginal cost of taxes decreases.

Thus, the central government has an incentive to set lower taxes on goods regions are more efficient at producing but higher taxes on goods regions are less efficient at producing. Given that the tax in the 
region with the comparative advantage has a stronger price effect than the tax in the other region, the inter-regional trade effect within a given sector is larger in the region with the comparative advantage. As the productivity gap between the two regions decreases $\left(\lambda_{i}^{-j}\right.$ increases $)$, the level of exports/imports falls by (12) and the trade effect thus weakens.

The inter-regional environmental effect can also amount to an increase or a decrease in the marginal cost of environmental taxes as higher taxes in region $j$ result in less pollution spilling over into region $-j$ (spillover effect) but more pollution being generated through an increase in local production in region $-j$ (own pollution effect). If pollution is a pure private good, there are no spillovers and the environmental effect thus increases the marginal cost of environmental taxes giving the central government an incentive to decrease taxes. However, if pollution is transboundary, the reduction in spillovers from lower production in region $j$ may more than offset the increase in pollution from higher production in region $-j$ so that the marginal cost of environmental taxes decreases and the central government opts for higher taxes. The more transboundary pollution is, the larger the reduction in spillovers from lower production in region $j$ and the stronger the central government's incentive to increase taxes; although the local production effect also increases with the extent to which pollution is transboundary, the change in the spillover effect dominates. Furthermore, when the own pollution effect dominates so that, overall, the environmental effect is positive (that is, a higher tax in region $j$ increases environmental damages in region $-j$ ), as the productivity gap between the two regions decreases, the environmental effect gets stronger in sector $i$ but can increase or decrease in sector $-i$. Correspondingly, when the spillover effect dominates so that, overall, the environmental effect is negative (that is, a higher tax in region $j$ decreases environmental damages in region $-j$ ), the environmental effect as the productivity gap between the two regions decreases gets stronger in sector $-i$ but can increase or decrease in sector $i$. In essence, a decrease in the productivity gap in sector $i$ triggers a decrease in production in region $j$, which weakens the spillover effect, and an increase in production in region $-j$, which strengthens the own pollution effect; a decrease in productivity gap in sector $-i$ triggers a decrease in production in region $-j$, which weakens the own pollution effect, and an increase in production in region $j$, which strengthens the spillover effect. ${ }^{2}$

Finally, the tax revenue effect is always positive in that a higher tax on good $i$ in region $j$ implies more production in region $-j$ and thus higher tax revenues; the smaller the productivity gap between the two regions is, the more region $-j$ produces in sector $i$ and thus the larger the tax effect.

\footnotetext{
${ }^{2}$ See Appendix for a formal derivation of the impact of a change in $s$ or $\lambda$ on the inter-regional environmental effect.
} 


\subsubsection{Central Environmental Policy}

Under a centralized system, a country chooses environmental taxes as to maximize its welfare which is given by the sum of the welfare levels of all of its regions. We can then express total welfare as

$$
W(\mathbf{t})=\sum_{j} \sum_{i}\left[C S_{i}^{j}(\mathbf{t})+P S_{i}^{j}(\mathbf{t})+T R_{i}^{j}(\mathbf{t})\right]-\sum_{j} \Psi^{j}(\mathbf{t})
$$

where $\mathbf{t}=\left[t_{a}^{A}, t_{b}^{A}, t_{a}^{B}, t_{b}^{B}\right]$ is the vector of environmental taxes, consumer surplus in region $j$ equals

$$
\sum_{i} C S_{i}^{j}=\frac{1}{2} \sum_{i}\left(\alpha-p_{i}^{j}\right)^{2}=\frac{1}{2}\left[\left(\alpha-p_{a}\right)^{2}+\left(\alpha-p_{b}\right)^{2}\right]
$$

producer surplus in region $j$ equals

$$
\begin{aligned}
\sum_{i} P S_{i}^{j} & =\sum_{i}\left[\left(p_{i}-t_{i}^{j}\right) x_{i}^{j}-\frac{\left(x_{i}^{j}\right)^{2}}{2 \lambda_{i}^{j}}\right] \\
& =\left(p_{a}-t_{a}^{j}\right) x_{a}^{j}+\left(p_{b}-t_{b}^{j}\right) x_{b}^{j}-\frac{1}{2}\left[\frac{\left(x_{a}^{j}\right)^{2}}{\lambda_{a}^{j}}+\frac{\left(x_{b}^{j}\right)^{2}}{\lambda_{b}^{j}}\right],
\end{aligned}
$$

tax revenue in region $j$ is given by

$$
\sum_{i} T R_{i}^{j}=t_{a}^{j} x_{a}^{j}+t_{b}^{j} x_{b}^{j}
$$

and environmental damage in region $j$ is given by (4), for $j=A, B$.

With environmental policy centrally set and thus maximizing the sum of region $A$ 's welfare and region $B$ 's welfare, we obtain the following equilibrium environmental taxes:

$$
t_{i}^{j}=\alpha\left\{\frac{2\left(1+s_{i}^{2}\right)+\left[\left(1-s_{i}^{2}\right)^{2}+4 s_{i}\right] \lambda_{i}^{-j}}{2\left(4+s_{i}^{2}\right)+\left[\left(1+s_{i}^{2}\right)^{2}+2\left(3-2 s_{i}\right)\right] \lambda_{i}^{-j}}\right\}
$$

and

$$
t_{i}^{-j}=\alpha\left\{\frac{4 s_{i}+\left(3+s_{i}^{4}\right) \lambda_{i}^{-j}}{2\left(4+s_{i}^{2}\right)+\left[\left(1+s_{i}^{2}\right)^{2}+2\left(3-2 s_{i}\right)\right] \lambda_{i}^{-j}}\right\} .
$$

Upon inspection of the two taxes, we have

Proposition 1 The larger the pollution spillover effects of production ( $\left.s_{i} \uparrow\right)$, the more heavily production is taxed $\left(t_{i}^{j} \uparrow\right.$ and $\left.t_{i}^{-j} \uparrow\right)$, independently of efficiency considerations (i.e., for any $\lambda_{i}^{-j}$ ). However, a narrowing in the productivity gap between the two regions $\left(\lambda_{i}^{-j} \uparrow\right)$ always yields a tax decrease in the less efficient region $\left(t_{i}^{-j} \uparrow\right)$ but decreases the tax in the more efficient region when pollution is relatively local $\left(t_{i}^{j} \downarrow\right.$ for $\left.0 \leq s_{i}<3-2 \sqrt{2}\right)$ and increases it otherwise $\left(t_{i}^{j} \uparrow\right.$ for $\left.3-2 \sqrt{2}<s_{i} \leq 1\right)$. 
That an increase in $s_{i}$ results in tax increases in both regions is fairly straightforward: the more damaging production is for a country's environmental quality (through larger spillovers from one region to the other), the higher the environmental taxes. The effects of changes in $\lambda_{i}^{-j}$ on taxes are however complicated by the presence of two offsetting effects as production changes have implications not only for local pollution but also for pollution in the other region. A decrease in the productivity gap in sector $i$ (that is, an increase in $\lambda_{i}^{-j}$ ), triggers a production decrease in the more efficient region and a production increase in the less efficient region. Less production in the more efficient region means that less pollution spills over into the less efficient region but, overall, pollution does increase in the latter region even in the extreme case when pollution is a pure public bad as, by (11), the production increase in this region exceeds the production decrease in the other region, and the environmental tax thus always increases in the less efficient region. On the other hand, the pollution level in the more efficient region decreases from lower local production but increases from higher production in the other region through spillovers; the stronger the spillover effects, the more likely the positive effect on pollution dominates so that the environmental tax in the more efficient region also increases; alternatively, when spillover effects are weak, the negative effect on pollution dominates so that the environmental tax in the more efficient region decreases.

When we compare the environmental taxes the two regions face on a given good, we obtain

Proposition 2 Under centrally set environmental policy, a good is taxed more heavily in the region which has a comparative advantage in its production, that is, $t_{a}^{A}>t_{a}^{B}$ and $t_{b}^{B}>t_{b}^{A}$; the tax difference is however smaller in the sector with a smaller productivity gap between the two regions and/or larger pollution spillovers, that is, $t_{a}^{A}-t_{a}^{B}<t_{b}^{B}-t_{b}^{A}$ if $\lambda_{a}^{B}>\lambda_{b}^{A}$ and/or $s_{a}>s_{b}$.

We can write the difference in environmental taxes between the two regions as

$$
t_{i}^{j}-t_{i}^{-j}=\frac{2 \alpha\left(1-s_{i}\right)^{2}\left(1-\lambda_{i}^{-j}\right)}{2\left(4+s_{i}^{2}\right)+\left[\left(1+s_{i}^{2}\right)^{2}+2\left(3-2 s_{i}\right)\right] \lambda_{i}^{-j}}>0 .
$$

If $s_{a}>s_{b}$ and/or $\lambda_{a}^{B}>\lambda_{b}^{A}$, we have that $t_{a}^{A}-t_{a}^{B}<t_{b}^{B}-t_{b}^{A}$ since

$$
\frac{\partial\left(t_{i}^{j}-t_{i}^{-j}\right)}{\partial s_{i}}=-\frac{4 \alpha\left(1-s_{i}\right)\left(1-\lambda_{i}^{-j}\right)\left[2\left(4+s_{i}\right)+\left(5+2 s_{i}^{3}-s_{i}^{4}\right) \lambda_{i}^{-j}\right]}{\left\{2\left(4+s_{i}^{2}\right)+\left[\left(1+s_{i}^{2}\right)^{2}+2\left(3-2 s_{i}\right)\right] \lambda_{i}^{-j}\right\}^{2}}<0
$$

and

$$
\frac{\partial\left(t_{i}^{j}-t_{i}^{-j}\right)}{\partial \lambda_{i}^{-j}}=-\frac{2 \alpha\left(1-s_{i}\right)^{2}\left(5+2 s_{i}+s_{i}^{2}\right)\left(3-2 s_{i}+s_{i}^{2}\right)}{\left\{2\left(4+s_{i}^{2}\right)+\left[\left(1+s_{i}^{2}\right)^{2}+2\left(3-2 s_{i}\right)\right] \lambda_{i}^{-j}\right\}^{2}}<0 .
$$


A regional comparative advantage results in greater production which generates greater pollution (and higher marginal damages) and is thus taxed at a higher rate. As spillovers increase, the larger production of a good in the more efficient region implies that more pollution spills over into the less efficient region so that the tax on the good increases in the latter region by more than in the former region. For example, when $s_{a}$ increases, more pollution from the production of good $a$ in region $A$ spills over into region $B$ than from the production of that same good in region $B$ into region $A$; while environmental taxes on the production of good $a$ increase in both regions, the tax in region $A$ increases by less than the tax in region $B$ and the difference between the two taxes, that is, $t_{a}^{A}-t_{a}^{B}$ decreases. When the productivity gap decreases and pollution is sufficiently transboundary so that total pollution increases in the more efficient region, the total pollution increase in the less efficient region exceeds that in the more efficient region. As a result, the tax increase in the latter region falls short of that in the former region and the difference between the two taxes thus decreases. That total pollution increases in the less efficient region by more than in the more efficient region follows from the fact that, unless pollution is perfectly transboundary (that is, $s_{i}=1$ ), lower production in the latter region has its strongest effect in terms of pollution reduction locally and, similarly, higher production in the former region has its stronger effect in terms of pollution increase locally.

When we compare the taxes on the two goods within a region, we have

Proposition 3 Under centrally set environmental policy, the tax in the sector in which a region has a comparative advantage is larger than the tax in the other sector when $s_{a}=s_{b}=s$ and $\lambda_{a}^{B}=\lambda_{b}^{A}=\lambda$ (e.g., $\left.t_{a}^{A}>t_{b}^{A}\right)$. However, if pollution is less transboundary in the more efficient sector than in the other sector (e.g., $\left.s_{a}<s_{b}\right)$, the tax difference $\left(t_{a}^{A}-t_{b}^{A}\right)$ is smaller; on the other hand, if the inter-sectoral productivity gap the region faces is larger than that in other region (e.g., $\lambda_{b}^{A}<\lambda_{a}^{B}$ so that $1-\lambda_{b}^{A}>1-\lambda_{a}^{B}$ ), the tax difference is larger.

When $s_{a}=s_{b}=s<1$ and $\lambda_{b}^{A}=\lambda_{a}^{B}=\lambda<1$,

$$
t_{i}^{j}-t_{-i}^{j}=\frac{2 \alpha(1-s)^{2}(1-\lambda)}{2\left(4+s^{2}\right)+\left[\left(1+s^{2}\right)^{2}+2(3-2 s)\right] \lambda}>0,
$$

for $j=A$ when $i=a$ (so that $-i=b$ ) and $j=B$ when $i=b$ (so that $-i=a$ ). The positive tax differential for $0 \leq s<1$ stems from the greater pollution region $j$ generates in sector $i$ relative to sector $-i$ : the smaller the productivity gap between the two regions is in each of the two sectors (that is, the larger the $\lambda)$ and/or the more transboundary pollution is in each of the two sectors (that is, the larger the $s$ ), the 
smaller the tax differential. In the extreme case in which pollution is a pure public bad in each of the two sectors $(s=1)$, region $j$ faces the same tax in each sector independently of its relative efficiency in sector $i$ (or region $-j$ 's relative efficiency in sector $-i$ ). In such a case, given that productivity gaps are the same in the two sectors, national production of good $i$ is the same as that of good $-i$ so that the total amount of pollution region $j$ faces from sector $-i$ is the same as that from sector $i$ even though region $j$ produces less of that good.

In the absence of inter-sectoral effects in tax setting, as per (18) and (19), we have that

$$
\frac{\partial\left(t_{i}^{j}-t_{-i}^{j}\right)}{\partial s_{i}}=\frac{\partial t_{i}^{j}}{\partial s_{i}} \text { and } \quad \frac{\partial\left(t_{i}^{j}-t_{-i}^{j}\right)}{\partial \lambda_{-i}^{j}}=-\frac{\partial t_{-i}^{j}}{\partial \lambda_{-i}^{j}}
$$

Using Proposition 1, we then obtain that, if $s_{i}<s_{-i}=s$, the environmental tax region $j$ faces on good $i$ falls relative to the tax it faces on good $-i$, and, if $\lambda_{-i}^{j}<\lambda_{i}^{-j}=\lambda$ (that is, region $j$ is more efficient at producing good $i$ relative to producing good $-i$ than region $-j$ is at producing good $-i$ relative to producing good $i$ ), the environmental tax region $j$ faces on good $-i$ decreases relative to the tax it faces on good $i$. When the pollution from the production of good $i$ in which region $j$ has a comparative advantage is relatively local, it is possible for the tax on good $-i$, where it has a comparative advantage, to be higher than the tax on good $i$. However, it is also possible for region $j$ to face a higher tax on good $i$ than on $\operatorname{good}-i$ when good $i$ 's pollution is perfectly local. In fact, for $s_{i}=0<s_{-i}=s$ and $\lambda_{-i}^{j}=\lambda_{i}^{-j}=\lambda$, that is, at values of $s_{i}$ and $\lambda_{-i}^{j}$ which give the lowest value for $t_{i}^{j}-t_{-i}^{j}$, the tax differential is equal to

$$
t_{i}^{j}-t_{-i}^{j}=-\frac{2 \alpha\left[\left(3 s^{4}-s^{2}+2 s+7\right) \lambda^{2}+\left(3 s^{4}-3 s^{2}+18 s+1\right) \lambda-s^{2}+16 s-8\right]}{(8+7 \lambda)\left\{2\left(4+s^{2}\right)+\left[\left(1+s^{2}\right)^{2}+2(3-2 s)\right] \lambda\right\}},
$$

which is always negative for any $\lambda$ provided that $2(2-\sqrt{3})<s \leq 1$ and for

$$
\lambda>-\frac{\left[\left(3 s^{4}-3 s^{2}+18 s+1\right)-\sqrt{\left(3 s^{4}-3 s^{2}+18 s+1\right)^{2}+4\left(3 s^{4}-s^{2}+2 s+7\right)\left(s^{2}-16 s+8\right)}\right]}{2\left(3 s^{4}-s^{2}+2 s+7\right)}
$$

when $0 \leq s<2(2-\sqrt{3})$.

Letting $s_{i}=\rho_{s} s_{-i}=\rho_{s} s$ and $\lambda_{-i}^{j}=\rho_{\lambda} \lambda_{i}^{-j}=\rho_{\lambda} \lambda$, with $0<\rho_{s}, \rho_{\lambda} \leq 1$, we show combinations of $s$ and $\lambda$ values yielding a negative tax differential $\left(t_{i}^{j}-t_{-i}^{j}<0\right)$ in Figure 1 for $\rho_{s}=0$ and $\rho_{\lambda}=1$, for $\rho_{s}=0.5$ and $\rho_{\lambda}=1$, and for $\rho_{s}=0$ and $\rho_{\lambda}=0.5$; as $\rho_{s}\left(s_{i}\right)$ increases and/or $\rho_{\lambda}\left(\lambda_{-i}^{j}\right)$ decreases, the curve shifts to the right so that it becomes less likely for the tax differential to be negative. When pollution is perfectly local in sector $i\left(\rho_{s}=0\right)$, total pollution region $j$ faces in sector $i$ decreases through lower local production in response to a decrease in productivity gap in sector $i$ (that is, as $\lambda_{i}^{-j}$ increases) and $t_{i}^{j}$ thus decreases. The greater the spillovers in sector $-i$, the higher the $t_{-i}^{j}$ so that $t_{i}^{j}$ falls short of $t_{-i}^{j}$ at high values of 
$\lambda_{i}^{-j}$ and $s_{-i}$ with a higher value of $\lambda_{i}^{-j}$ (and thus lower $t_{i}^{j}$ ) requiring a lower value of $s_{-i}$ (and thus lower $t_{-i}^{j}$ ) for the tax differential to be negative. As $s_{i}$ increases ( $\rho_{s}$ increases), $t_{i}^{j}$ increases relative to $t_{-i}^{j}$; as $\lambda_{-i}^{j}$ decreases ( $\rho_{\lambda}$ decreases), that is, the productivity gap in sector $i$ becomes larger than the productivity gap in sector $-i, t_{-i}^{j}$ decreases relative to $t_{i}^{j}$ as total pollution region $j$ faces in sector $-i$ falls through a decrease in local production which outweighs the production increase in region $-j$.

Harmonized Taxes As central governments do not tend to resort to differential tax systems, we further consider central policy under the constraint that taxes in a given sector be equal between the two regions (that is, taxes are harmonized). Letting $t_{i}^{h}$ denote the harmonized tax rate in sector $i(i=a, b)$, we derive the optimal environmental policy maximizing the country's welfare given in (14) as comprising

$$
t_{a}^{h}=\frac{\alpha\left[\left(s_{a}+\lambda_{a}^{B}\right)^{2}+\left(1+s_{a} \lambda_{a}^{B}\right)^{2}\right]}{4+s_{a}^{2}+\lambda_{a}^{B}\left(4+s_{a}^{2} \lambda_{a}^{B}+4 s_{a}+2 \lambda_{a}^{B}\right)}
$$

and

$$
t_{b}^{h}=\frac{\alpha\left[\left(s_{b}+\lambda_{b}^{A}\right)^{2}+\left(1+s_{b} \lambda_{b}^{A}\right)^{2}\right]}{4+s_{b}^{2}+\lambda_{b}^{A}\left(4+s_{b}^{2} \lambda_{b}^{A}+4 s_{b}+2 \lambda_{b}^{A}\right)} .
$$

In comparison to the unharmonized taxes expressed in (18) and (19), the harmonized taxes are lower on goods in which regions have a comparative advantage but higher otherwise, that is,

$$
t_{a}^{B}<t_{a}^{h}<t_{a}^{A} \quad \text { and } \quad t_{b}^{A}<t_{b}^{h}<t_{b}^{B}
$$

Under harmonized taxes, the less efficient region thus subsidizes the more efficient region; the tax increase in the former $\left(t_{i}^{h}-t_{i}^{-j}\right)$ is however larger than the tax decrease $\left(t_{i}^{j}-t_{i}^{h}\right)$ in the latter as long as pollution is not a pure public bad (see Appendix A). In fact, for $s_{i}<1$, the marginal environmental damage of production in sector $i$ is greater in region $j$ than in region $-j$ due to the quadratic nature of the damage function as region $j$, being the more efficient producer in sector $i$, produces more of good $i$ than region $-j$. Hence, a unit tax reduction in sector $i$ increases pollution in region $j$ by more than a unit tax increase reduces pollution in region $-j$ so that the harmonized tax maximizing a country's welfare is chosen between $t_{i}^{-j}$ and $t_{i}^{j}$ but closer to $t_{i}^{j}$ than to $t_{i}^{-j}$. If no productivity gap exists between the two regions in sector $i$ (i.e. $\lambda_{i}^{-j}=\lambda_{i}^{j}=1$ ), the two regions will have the same level of production in sector $i$ and face the same marginal environmental damage of production independently of the transboundary nature of pollution; hence, the harmonized tax will be exactly equal to the average of the two unharmonized taxes.

In terms of environmental damages, the unharmonized policy always results in a better environment when pollution spillovers occur according to the same positive rate across sectors (i.e., $0<s_{a}=s_{b}<1$ ) and 
productivity gaps are the same across regions (i.e., $0<\lambda_{a}^{B}=\lambda_{b}^{A}<1$ ). ${ }^{3}$ When moving to harmonization, the tax changes imply production increases in the comparative advantage sector but decreases in the other sector; in the absence of differences in spillover effects and productivity gaps, the production increase in the comparative advantage sector dominates so that, overall, environmental damages are larger under harmonization. However, it is possible for a region to enjoy a better environment under harmonized taxes if the pollution generated in the comparative advantage sector is more transboundary than the pollution generated in the other sector and/or if the cross-sectoral productivity gap it faces is smaller than the crosssectoral productivity gap the other region faces. An increase in $s_{i}$ reduces the gap between pollution under unharmonized taxes and pollution under harmonized taxes in sector $i$ (through a reduction in the tax gap and thus in the production gap) but does not alter the pollution gap in sector $-i$. Given that pollution from sector $i$ is higher in region $j$ but lower in region $-j$ (and, correspondingly, pollution from sector $-i$ is higher in region $-j$ but lower in region $j$ ) under harmonized taxes, the reduction in sector $i$ 's pollution gap that follows the increase in $s_{i}$ amounts not only to a lower pollution cost of harmonization in region $j$ but also to a lower pollution benefit of harmonization in region $-j$. While the overall environmental cost of harmonization increases in region $-j$ (that is, the region which does not have a comparative advantage in sector $i$ ), region $j$ may end up being environmentally better off under harmonized policy as the reduction in the pollution gap in sector $i$ may be such that the benefit from lower pollution in sector $-i$ (which is not affected by an increase in $s_{i}$ ) more than offsets the cost from higher pollution in sector $i$ (which decreases following an increase in $s_{i}$ ). In Figure 2a, we illustrate the impact of an increase in $s_{i}$ on environmental damages given $\alpha, \lambda_{i}^{-j}, \lambda_{-i}^{j}$, and $s_{-i}$.

The effect of a deviation in the productivity gap between the two regions (e.g., when $\lambda_{i}^{-j}>\lambda_{-i}^{j}$, that is, region $-j$ 's inter-sectoral productivity gap is smaller than region $i$ 's) is less straightforward: from a position of equality in spillover effects between the two sectors and productivity gaps between the two regions, an increase in $\lambda_{i}^{-j}$, ceteris paribus, can increase or decrease the environmental cost of harmonization in region $j$ (as illustrated in Figure 2b, the increase occurs at low values of $\lambda_{i}^{-j}$ or in areas $Q$ and $R$ ) and increase or decrease its environmental benefit in region $-j$ (in Figure $2 \mathrm{~b}$, the increase occurs at combinations of low values of $\lambda_{i}^{-j}$ and high values of $s_{i}$ or in area $Q$ ). By (11), the magnitude of the impact of a change in $\lambda_{i}^{-j}$ depends on the production level of good $i$ in region $-j$ : the more region $-j$ produces, the stronger the effects of an increase in $\lambda_{i}^{-j}$ on good $i$ 's production levels in the two regions. As region $-j$ 's production level of good $i$ is lower under harmonized policy, an increase in $\lambda_{i}^{-j}$ increases the gap in good $i$ 's production

\footnotetext{
${ }^{3}$ In the extreme case in which pollution is a pure public bad in both sectors (i.e., $s_{a}=s_{b}=1$ ), environmental quality is the same independently of whether taxes are harmonized.
} 
between unharmonized and harmonized taxes in each region. However, a change in $\lambda_{i}^{-j}$ also affects the tax gaps: a lower productivity gap between the two regions (i.e., a higher $\lambda_{i}^{-j}$ ) does in fact amount to less variation between the two regions in the absence of harmonization and thus to a lower tax effect of harmonization; a lower tax gap then implies a lower gap between production under unharmonized taxes and production under harmonized taxes. The lower the productivity advantage that region $j$ enjoys in sector $i$ relative to region $-j$ is (that is, the higher $\lambda_{i}^{-j}$ is), the less effective an increase in $\lambda_{i}^{-j}$ is in increasing region $-j$ 's production of good $i$ and the closer the taxes the two regions face in sector $i$ under unharmonized policy are. ${ }^{4}$ Hence, at high values of $\lambda_{i}^{-j}$, the effects of an increase in $\lambda_{i}^{-j}$ on the tax gaps tend to prevail and the production gaps thus tend to decrease, that is, harmonization tends to yield a lower production increase in the efficient region and a lower production decrease in the other region. For a given $s_{i}$, pollution is then more likely to decrease (increase) in region $j$ and increase (decrease) in region $-j$ as $\lambda_{i}^{-j}$ increases at low (high) values of $\lambda_{i}^{-j}$. As $s_{i}$ increases, the lower pollution increase region $-j$ experiences under harmonization has a greater impact on region $j$ 's total pollution and lower values of $\lambda_{i}^{-j}$ are then required for region $j$ 's pollution to increase in response to an increase in $\lambda_{i}^{-j}$. At the same time, the lower pollution decrease region $j$ experiences under harmonization has a greater impact on region $-j$ 's total pollution and higher values of $\lambda_{i}^{-j}$ are required for region $-j$ 's pollution to decrease in response to an increase in $\lambda_{i}^{-j}$. In light of the above, it is possible for the region with a comparative advantage in sector $i$ to enjoy a better environment under harmonized policy at high values of $\lambda_{i}^{-j}$ (area $S$ in Figure $2 \mathrm{~b}$ ) and for the region which is less efficient in sector $i$ to face less pollution under harmonized taxes at combinations of low values of $\lambda_{i}^{-j}$ and high values of $s_{i}$ (area $Q$ in Figure 2b). In Figure 2c, we illustrate the impact of an increase in $\lambda_{i}^{-j}$ on environmental damages given $\alpha, s_{i}, s_{-i}$, and $\lambda_{-i}^{j}$.

\subsubsection{Regional Environmental Policy}

Under a decentralized system, each of the two regions (e.g., region $j$ ) chooses the environmental taxes to levy on the production of the two goods as to maximize its welfare which is given by

$$
W^{j}\left(\widetilde{\mathbf{t}}^{j}\right)=\sum_{i}\left[C S_{i}^{j}\left(\widetilde{\mathbf{t}}^{j}\right)+P S_{i}^{j}\left(\widetilde{\mathbf{t}}^{j}\right)+T R_{i}^{j}\left(\widetilde{\mathbf{t}}^{j}\right)\right]-\Psi^{j}\left(\widetilde{\mathbf{t}}^{j}\right)
$$

where $\widetilde{\mathbf{t}}^{j}=\left[\widetilde{t}_{a}^{j}, \widetilde{t}_{b}^{j}\right]$ is the vector of environmental taxes in region $j$ and consumer surplus, producer surplus, tax revenue, and environmental damage in region $j$ are expressed in (15) through (17) and (4), respectively.

\footnotetext{
${ }^{4}$ Using (11), we have that

$$
\frac{\partial^{2} x_{i}^{j}}{\partial\left(\lambda_{i}^{-j}\right)^{2}}=\frac{2 \lambda_{i}^{-j} x_{i}^{-j}}{\left[\lambda_{i}^{-j}\left(3+\lambda_{i}^{-j}\right)\right]^{2}}>0 \quad \text { and } \quad \frac{\partial^{2} x_{i}^{-j}}{\partial\left(\lambda_{i}^{-j}\right)^{2}}=-\frac{6 \lambda_{i}^{-j} x_{i}^{-j}}{\left[\lambda_{i}^{-j}\left(3+\lambda_{i}^{-j}\right)\right]^{2}}<0 .
$$
}


The decentralized environmental taxes are thus given by

$$
\widetilde{t}_{i}^{-j}=\frac{\alpha}{\widetilde{n}_{i}}\left[\left(s_{i}^{4}-4 s_{i}^{3}+3 s_{i}^{2}+6 s_{i}-12\right)\left(\lambda_{i}^{-j}\right)^{2}+\left(-2 s_{i}^{3}+9 s_{i}^{2}-4 s_{i}-25\right) \lambda_{i}^{-j}+4\left(s_{i}^{2}-3 s_{i}+1\right)\right]
$$

and

$$
\widetilde{t}_{i}^{j}=\frac{\alpha}{\widetilde{n}_{i}}\left[\left(s_{i}^{4}-4 s_{i}^{3}+9 s_{i}^{2}-2 s_{i}-4\right)\left(\lambda_{i}^{-j}\right)^{2}+\left(-2 s_{i}^{3}+7 s_{i}^{2}-8 s_{i}-11\right) \lambda_{i}^{-j}-18\right]
$$

where

$$
\widetilde{n}_{i}=\left(s_{i}^{4}-4 s_{i}^{3}-s_{i}^{2}+16 s_{i}-26\right)\left(\lambda_{i}^{-j}\right)^{2}+\left(-2 s_{i}^{3}+5 s_{i}^{2}+22 s_{i}-85\right) \lambda_{i}^{-j}-54<0 .
$$

When we consider the sector in which a region does not have a comparative advantage (e.g., sector $a$ for region $B$ and sector $b$ for region $A$ ) and compare the relevant centralized taxes given in (18) and (19) with the corresponding decentralized taxes given in (30) and (31), we obtain

Proposition 4 The environmental tax on the good which a region is less efficient at producing is always higher under a centralized system than under a decentralized system, that is, $t_{b}^{A}>\widetilde{t}_{b}^{A}$ and $t_{a}^{B}>\widetilde{t}_{a}^{B}$.

We can express the difference in the environmental taxes region $-j$ faces on good $i$ under the two policy regimes as

$$
t_{i}^{-j}-\widetilde{t}_{i}^{-j}=-\frac{2 \alpha\left\{\xi_{1}\left(\lambda_{i}^{-j}\right)^{3}+\xi_{2}\left(\lambda_{i}^{-j}\right)^{2}+\xi_{3} \lambda_{i}^{-j}+\left[-3\left(\lambda_{i}^{-j}\right)^{3}-8\left(\lambda_{i}^{-j}\right)^{2}-5 \lambda_{i}^{-j}+16\right]\right\}}{\widetilde{n}_{i}\left\{2\left(4+s_{i}^{2}\right)+\left[\left(1+s_{i}^{2}\right)^{2}+2\left(3-2 s_{i}\right)\right] \lambda_{i}^{-j}\right\}}>0
$$

where $\xi_{1}, \xi_{2}$, and $\xi_{3}$ are positive parameters. ${ }^{5}$ For the sector in which a region does not have a comparative advantage and must thus import from the other region, the inter-regional trade effect and the tax revenue effect work in the same direction to increase the marginal benefit of environmental taxes. The combined positive effect on tax setting stems from an increase in the value of trade and the additional tax revenues region $j$ enjoys through higher production. At low values of $s_{i}$, the inter-regional environmental trade effect works in the opposite direction to increase the marginal cost of environmental taxes as higher production in region $j$ yields higher pollution. However, even in the extreme case when $s_{i}=0$ (that is, pollution is perfectly local in sector $i$ ), the combined positive effect from trade and tax revenue more than offsets the negative environmental effect so that, overall, the central government always opts for a higher tax than the regional government in the comparative advantage sector.

For the sector in which a region does have a comparative advantage, we instead obtain

\footnotetext{
${ }^{5}$ Specifically, $\xi_{1}=3 s_{i}^{6}-11 s_{i}^{5}+20 s_{i}^{4}-8 s_{i}^{3}-12 s_{i}^{2}+21 s_{i}>0, \xi_{2}=3 s_{i}^{6}-21 s_{i}^{5}+58 s_{i}^{4}-34 s_{i}^{3}-25 s_{i}^{2}+79 s_{i}>0$, and $\xi_{3}=2 s_{i}^{6}-8 s_{i}^{5}+46 s_{i}^{4}-42 s_{i}^{3}+9 s_{i}^{2}+104 s_{i}>0$.
} 
Proposition 5 The environmental tax on the good which a region is more efficient at producing is higher under a centralized system when the production of the good generates substantial pollution spillovers. For sufficently low values of $s_{i}$, there exists however a productivity gap between the two regions above which the tax is higher under a decentralized system, with a smaller $s_{i}$ requiring a smaller productivity gap for the tax to be higher under a decentralized system.

We can express the difference in the environmental taxes region $j$ faces on good $i$ under the two policy regimes as

$$
t_{i}^{j}-\widetilde{t}_{i}^{j}=-\frac{2 \alpha\left\{\zeta_{1}\left(\lambda_{i}^{-j}\right)^{3}+\zeta_{2}\left(\lambda_{i}^{-j}\right)^{2}+\left[\zeta_{3}-\left(\lambda_{i}^{-j}\right)^{2}+14 \lambda_{i}^{-j}+5\right] \lambda_{i}^{-j}+\left(36 s_{i}^{2}-18\right)\right\}}{\tilde{n}_{i}\left\{2\left(4+s_{i}^{2}\right)+\left[\left(1+s_{i}^{2}\right)^{2}+2\left(3-2 s_{i}\right)\right] \lambda_{i}^{-j}\right\}},
$$

where $\zeta_{1}, \zeta_{2}$, and $\zeta_{3}$ are positive parameters. ${ }^{6}$ Hence, $t_{i}^{j}-\widetilde{t}_{i}^{j}$ is always positive for $s_{i}>\sqrt{0.5}$ and is positive otherwise, provided that $\lambda_{i}^{-j}$ is not too small; for $s_{i}<\sqrt{0.5}$, the lower $s_{i}$ is, the larger the $\lambda_{i}^{-j}$ needed for $t_{i}^{j}-\widetilde{t}_{i}^{j}$ to be positive. When pollution arising from the production of good $i$ is perfectly local (i.e., $s_{i}=0$ ), the environmental tax on good $i$ in region $j$ is larger under the decentralized regime than under the centralized regime for any productivity gap between the two regions (that is, for any value of $\lambda_{i}^{-j}$ ); when $s_{i}=0,(34)$ in fact reduces to

$$
t_{i}^{j}-\widetilde{t}_{i}^{j}=\frac{2 \alpha\left\{\left[-\left(\lambda_{i}^{-j}\right)^{2}+14 \lambda_{i}^{-j}+5\right] \lambda_{i}^{-j}-18\right\}}{26\left(\lambda_{i}^{-j}\right)^{2}+463 \lambda_{i}^{-j}+432}<0 .
$$

In the determination of the environmental tax on the good in which a region has a comparative advantage, the inter-regional environmental effect and tax revenue effect work in the same manner as in the setting of the tax on the inefficiently produced good above considered, increasing the tax rate as spillovers increase. However, the inter-regional trade effect not only works in the opposite direction as lower taxes generate benefits to consumers in two regions rather than one, thus decreasing the tax rate, but is also larger in magnitude because of the larger price effect of the tax in the more efficient sector. When pollution is perfectly local, the inter-regional environmental effect consists solely of the own pollution effect and thus reenforces the inter-regional trade effect in lowering the central tax relative to the regional tax. As pollution becomes less local, the spillover effect increases, counteracting the own pollution effect and eventually changing the direction of the inter-regional environmental effect. For a given productivity gap between the two regions, there exists a $s_{i}$ above which the positive inter-regional environmental effect coupled

\footnotetext{
${ }^{6}$ Specifically, $\zeta_{1}=7 s_{i}^{6}-21 s_{i}^{5}+38 s_{i}^{4}-14 s_{i}^{3}-26 s_{i}^{2}+45 s_{i}>0, \zeta_{2}=s_{i}^{6}-19 s_{i}^{5}+70 s_{i}^{4}-46 s_{i}^{3}-43 s_{i}^{2}+129 s_{i}>0$, and $\zeta_{3}=20 s_{i}^{4}-36 s_{i}^{3}+25 s_{i}^{2}+90 s_{i}>0$.
} 
with the tax revenue effect more than offsets the negative inter-regional trade effect and the central tax is greater than the regional tax. The smaller the productivity gap between the two regions is, the weaker the inter-regional trade effect because of the lower trade volume and thus the smaller the spillover effect that is necessary for the central tax to be greater than the regional tax. We show the critical value of $s_{i}$ as a function of $\lambda_{i}^{-j}$ such that $t_{i}^{j}-\widetilde{t}_{i}^{j}=0$, thus solving (34), in Figure 3 ; in the dark grey area, below the critical $s_{i}$ curve, the centrally set tax on the good in which a region has a comparative advantage is smaller than the corresponding tax under a decentralized system.

As the case under a centralized regime, a good is taxed more heavily under a decentralized system in the region which enjoys a comparative advantage in its production, that is,

$$
\widetilde{t}_{i}^{j}-\widetilde{t}_{i}^{-j}=-\frac{2 \alpha\left(1-\lambda_{i}^{-j}\right)\left[\left(3 s_{i}^{2}-4 s_{i}+4\right) \lambda_{i}^{-j}+2 s_{i}^{2}-6 s_{i}+11\right]}{\widetilde{n}_{i}}>0
$$

the difference is however smaller under a centralized system, that is, $t_{i}^{j}-t_{i}^{-j}<\widetilde{t}_{i}^{j}-\widetilde{t}_{i}^{-j}$ or

$$
\left(t_{i}^{j}-t_{i}^{-j}\right)-\left(\widetilde{t}_{i}^{j}-\widetilde{t}_{i}^{-j}\right)=\frac{4\left(1-\lambda_{i}^{-j}\right)\left(\phi_{1}\left(\lambda_{i}^{-j}\right)^{2}+\phi_{2} \lambda_{i}^{-j}+\phi_{3}\right)}{\widetilde{n}_{i}\left\{2\left(4+s_{i}^{2}\right)+\left[\left(1+s_{i}^{2}\right)^{2}+2\left(3-2 s_{i}\right)\right] \lambda_{i}^{-j}\right\}}<0
$$

where $\phi_{1}, \phi_{2}$, and $\phi_{3}$ are positive parameters. ${ }^{7}$ We can then conclude that, when central taxes are greater than local taxes in both sectors, the tax premium under a centralized system is larger in the region that is less efficient at producing the good, that is, $t_{i}^{-j}-\widetilde{t}_{i}^{-j}>t_{i}^{j}-\widetilde{t}_{i}^{j}$. The presence of the inter-regional trade effect in the setting of central taxes is at the core of this result: a tax increase in the sector in which a region enjoys an exporting position yields a price increase that generates a net cost to the importing region as the gain in producer surplus falls short of the loss in consumer surplus. A tax increase in the sector in which a region imports yields a price increase that generates a net benefit to the exporting region as the gain in producer surplus more than offsets the loss in consumer surplus. Hence, the inter-regional trade effect serves to curb the central government's incentive to impose higher taxes for goods regions export but to re-enforce it for goods regions import.

When we compare the taxes within a given region, we find that, as in the central policy case, the good in which the region has a comparative advantage may be taxed at a higher or lower rate depending on differences in the transboundary nature of pollution between the two production processes as well as differences in comparative advantage between the two regions. The tax differential, which is positive and equal to the within sector tax differential given in (36) in the absence of differences in spillover effects

\footnotetext{
${ }^{7}$ Specifically, $\phi_{1}=2 s_{i}^{6}-5 s_{i}^{5}+9 s_{i}^{4}-3 s_{i}^{3}-7 s_{i}^{2}+12 s_{i}+1>0, \phi_{2}=s_{i}^{6}-4 s_{i}^{5}+15 s_{i}^{4}-9 s_{i}^{3}-16 s_{i}^{2}+37 s_{i}+12>0$, and $\phi_{3}=2 s_{i}^{4}-6 s_{i}^{3}-8 s_{i}^{2}+30 s_{i}+17>0$.
} 
and productivity gaps, is however monotonic in each of the four parameters, namely, $s_{a}, s_{b}, \lambda_{a}^{B}$, and $\lambda_{b}^{A}$; specifically,

$$
\frac{\partial\left(\widetilde{t}_{i}^{j}-\widetilde{t}_{-i}^{j}\right)}{\partial s_{i}}>0, \quad \frac{\partial\left(\widetilde{t}_{i}^{j}-\widetilde{t}_{-i}^{j}\right)}{\partial s_{-i}}<0, \quad \frac{\partial\left(\widetilde{t}_{i}^{j}-\widetilde{t}_{-i}^{j}\right)}{\partial \lambda_{i}^{-j}}<0, \quad \frac{\partial\left(\widetilde{t}_{i}^{j}-\widetilde{t}_{-i}^{j}\right)}{\partial \lambda_{-i}^{j}}<0 .
$$

Therefore, the stronger the pollution spillovers of good $i$ are relative to the pollution spillovers of good $-i$, the higher the tax region $j$ faces on good $i$, the good which it produces more efficiently and thus it exports to the other region, relative to the tax it faces on good $-i$. Consistently with this result, we have that

$$
\frac{\partial\left(\widetilde{t}_{i}^{j}-\widetilde{t}_{-i}^{j}\right)}{\partial \rho_{s}}>0
$$

where $\rho_{s}=\frac{s_{i}}{s_{-i}}$. Although a reduction in the comparative advantage region $j$ enjoys in the production of good $i$ has the same qualitative effect on the tax differential as a reduction in the comparative advantage region $-j$ enjoys in the production of good $-i$, the latter has a stronger effect as reflected in

$$
\frac{\partial\left(\widetilde{t}_{i}^{j}-\widetilde{t}_{-i}^{j}\right)}{\partial \rho_{\lambda}}<0
$$

where $\rho_{\lambda}=\frac{\lambda_{-i}^{j}}{\lambda_{i}^{-j}}$; in other words, a decrease in the productivity advantage region $j$ has in the production of good $i$ (i.e., increase in $\lambda_{i}^{-j}$ ) reduces the tax region $j$ pays on good $i$ relative to the tax it pays on good $-i$ by a smaller amount than an equal decrease in the productivity advantage region $-j$ has in the production of good $-i$ (i.e., increase in $\left.\lambda_{-i}^{j}\right){ }^{8}$ An increase in productivity increases production in the importing region by more than it decreases production in the exporting region. This differential effect on production has implications for a region's incentive to increase or decrease its environmental tax in the affected sector. Trade increases the cost of taxation in the importing region but decreases it (or, equivalently, increases the benefit of taxation) in the exporting region; the larger the volume of trade volume is, the higher the cost or benefit of taxation is depending on the direction of trade. A larger increase in production in the importing region in response to an increase in productivity (which results in less dependence on imports in spite of the increase in local consumption following a price reduction) amounts to a larger reduction in the cost of taxation, or a stronger weakening of the incentive to lower the tax on the imported good, than

\footnotetext{
${ }^{8}$ The effect of $\rho_{\lambda}$ on the tax difference can be written in terms of $\lambda_{i}^{-j}$ and $\lambda_{-i}^{j}$ as

$$
\frac{1}{\lambda_{i}^{-j}}\left[\frac{\partial\left(\widetilde{t}_{i}^{j}-\widetilde{t}_{-i}^{j}\right)}{\partial \lambda_{-i}^{j}}-\rho_{\lambda} \frac{\partial\left(\widetilde{t}_{i}^{j}-\widetilde{t}_{-i}^{j}\right)}{\partial \lambda_{i}^{-j}}\right]<0
$$

As $\rho_{\lambda} \in(0,1]$ and $\frac{\partial\left(\tilde{t}_{i}^{j}-\widetilde{t}_{-i}^{j}\right)}{\partial \lambda_{i}^{-j}}=\frac{\partial \widetilde{t}_{i}^{j}}{\partial \lambda_{i}^{-j}}$ and $\frac{\partial\left(\tilde{t}_{i}^{j}-\tilde{t}_{-i}^{j}\right)}{\partial \lambda_{-i}^{j}}=-\frac{\partial \tilde{t}_{-i}^{j}}{\partial \lambda_{-i}^{j}}$, the direction of the effect for any feasible $\rho_{\lambda}$ value implies that $\frac{\partial \widetilde{t}_{-i}^{j}}{\partial \lambda_{-i}^{j}}>\left|\frac{\partial \widetilde{t}_{i}^{j}}{\partial \lambda_{i}^{-j}}\right|$. See Appendix.
} 
the reduction in the benefit of taxation in the exporting region from a decrease in production and thus exports. ${ }^{9}$ Hence, a decrease in productivity gap has a stronger tax effect in the importing region. ${ }^{10}$

In setting taxes, a region takes into account the effects that these instruments have on total surplus, tax revenues, and environmental damages. Independently of whether the region has a comparative advantage in a given sector, it faces a trade-off between generating more tax revenues through greater production which requires lower taxes and keeping the environment cleaner through lower production and thus higher taxes. The tax effect on total surplus is however linked to the direction and extent of trade and therefore to the presence and extent of a comparative advantage; a tax increase does in fact generate net benefits through higher prices of exports (in the comparative advantage sector) but net costs through higher prices of imports (in the other sector). The additional benefits of taxes on goods regions are more efficient at producing translate into higher taxes; conversely, the additional costs of taxes on goods regions are less efficient at producing translate into lower taxes. Clearly, the larger the extent of trade is as a result of a greater productivity gap between the two regions, the greater the revenue from exports or the cost of imports is; hence, as the volume of trade increases, the exporting region faces a stronger incentive to increase its tax while the importing region faces a stronger incentive to decrease its tax. Correspondingly, the smaller the productivity gap is, the smaller the revenue from exports or the cost of imports is and the weaker the exporting region's incentive to increase its tax or the importing region's incentive to decrease its tax. This convergence of incentives amounts to a decrease in the tax gap between exporting and importing regions within a given sector and between exporting and importing sectors within a given region.

Aside from differences in the direction of incentives stemming from trade considerations, there exist differences in the strength of incentives arising from environmental considerations. As long as pollution generated in a given sector is not perfectly transboundary, its level and the associated benefit of a tax increase are higher in the region that produces more, that is, the region with a comparative advantage. The more transboundary pollution is in a given sector, the smaller the pollution gap between the two regions and, correspondingly, the smaller the tax gap. Put differently, although each region faces a larger pollution level and thus a greater incentive to increase its tax as pollution becomes more transboundary, the importing region (that is, the region producing less), faces a larger increase in pollution and thus a

\footnotetext{
${ }^{9} \mathrm{~A}$ decrease in productivity gap between the two regions reduces the price level and thus increases local consumption in both regions. Exports thus fall by more than local production.

${ }^{10}$ The tax implications of the differential effect on production of a decrease in productivity gap may also be linked to environmental considerations. In fact, unless pollution in the exporting sector is substantially more transboundary than pollution in the importing sector, overall pollution increases in the latter by more than in the former, thus providing a region with additional incentives to increase its tax on the imported good. A decrease in productivity gap in the sector in which a region has a comparative advantage does in fact reduce pollution in that sector, provided that its spillover effects are not significant.
} 
greater incentive to increase its tax.

Finally, when we compare the above tax differential under the two policy regimes, we have that

$$
\left(t_{i}^{j}-t_{-i}^{j}\right)-\left(\widetilde{t}_{i}^{j}-\widetilde{t}_{-i}^{j}\right)<0
$$

that is, the tax differential is always smaller under a centralized system. In fact, as

$$
\frac{\partial\left[\left(t_{i}^{j}-t_{-i}^{j}\right)-\left(\widetilde{t}_{i}^{j}-\widetilde{t}_{-i}^{j}\right)\right]}{\partial \rho_{s}}>0 \quad \text { and } \frac{\partial\left[\left(t_{i}^{j}-t_{-i}^{j}\right)-\left(\widetilde{t}_{i}^{j}-\widetilde{t}_{-i}^{j}\right)\right]}{\partial \rho_{\lambda}}>0
$$

we obtain the lower bound value of the difference of the two tax differentials when $\rho_{\lambda}=\rho_{s}=0$ and the upper bound value when $\rho_{\lambda}=\rho_{s}=1$. The latter turns out to be exactly equal to $\left[\left(t_{i}^{j}-t_{i}^{-j}\right)-\left(\widetilde{t}_{i}^{j}-\widetilde{t}_{i}^{-j}\right)\right]$ as given in (37) for $s_{i}=s_{-i}=s$ and $\lambda_{i}^{-j}=\lambda_{-i}^{j}=\lambda$ and is thus negative so that $\left[\left(t_{i}^{j}-t_{-i}^{j}\right)-\left(\widetilde{t}_{i}^{j}-\widetilde{t}_{-i}^{j}\right)\right]$ must be negative for any combination of feasible $\rho_{s}$ and $\rho_{\lambda}$ values. That the gap between the two taxes within a region is narrower under a centralized regime follows directly from the presence of the interregional trade effect which reduces the benefit of taxes for exported good but increases it for imported goods.

\subsection{Assessing the Environment: Central versus Regional Policy}

In assessing the environmental impact of central policy versus local policy, we compare the environmental damages in region $j$ under the two tax regimes. We initially consider a situation in which productivity gaps are the same between the two regions and spillover effects are the same between the two goods. Our initial case involves $s_{i}=s$ and $\lambda_{i}^{-j}=\lambda$ so that we need only assess environmental differences for one of the two regions (e.g., region $j$ ).

Using the damage function given in (4), the central taxes in (18) and (19), and the local taxes in (30) and (31), we can express the difference between the environmental damage under a centralized system and the environmental damage under a decentralized system as

$$
\begin{aligned}
\Psi^{j}(\boldsymbol{\lambda}, \mathbf{s}) \equiv & \psi^{j}-\widetilde{\psi}^{j}=\frac{1}{4} \sum_{i=a, b} \frac{1}{\left(3+\lambda_{i}^{-j}\right)^{2}}\left\{\lambda_{i}^{-j}\left(t_{i}^{-j}-\widetilde{t}_{i}^{-j}\right)\left[4 \alpha e_{1 i} e_{2 i}+\lambda_{i}^{-j} e_{2 i}^{2}\left(t_{i}^{-j}+\widetilde{t}_{i}^{-j}\right)\right]+\right. \\
& \left.+\left(t_{i}^{j}-\widetilde{t}_{i}^{j}\right)\left[4 \alpha e_{2 i} e_{3 i}+e_{3 i}^{2}\left(t_{i}^{j}+\widetilde{t}_{i}^{j}\right)\right]+2 \lambda_{i}^{-j} e_{1 i} e_{3 i}\left(t_{i}^{j} t_{i}^{-j}-\widetilde{t}_{i}^{j} \widetilde{t}_{i}^{-j}\right)\right\},
\end{aligned}
$$

where $j=A(B)$ and $-j=B(A)$ when $i=a(b), \boldsymbol{\lambda}=\left[\lambda_{a}^{B}, \lambda_{b}^{A}\right]$ and $\mathbf{s}=\left[s_{a}, s_{b}\right]$ are the vectors of productivity gaps and spillover effects, and $e_{1 a}=\left(1-3 s_{a}\right), e_{1 b}=\left(s_{b}-3\right), e_{2 a}=\left(1+s_{a} \lambda_{a}^{B}\right), e_{2 b}=$ $\left(\lambda_{b}^{A}+s_{b}\right), e_{3 a}=\left(s_{a} \lambda_{a}^{B}-\lambda_{a}^{B}-2\right)$, and $e_{3 b}=\left(\lambda_{b}^{A}-s_{b} \lambda_{b}^{A}-2 s_{b}\right)$. Upon inspection of the above difference, we have 
Proposition 6 When the two goods have identical spillover effects (i.e., $s_{a}=s_{b}=s$ ) and the two regions enjoy the same productivity gaps in absolute terms (i.e., $\lambda_{a}^{A}-\lambda_{b}^{A}=\lambda_{b}^{B}-\lambda_{a}^{B}=1-\lambda$ ), environmental damages from production can be larger under a centralized regime. In particular, for a given productivity gap $(\lambda)$, damages tend to be lower under a decentralized regime when pollution from each of the two goods is relatively local (at low values of $s$ ). The smaller the productivity gap (the larger the $\lambda$ ), the more local pollution has to be (the smaller the s) for damages to be lower under local taxes.

Letting $\widehat{s}$ satisfy $\Psi^{j}(\lambda, s)=0$, we have that

$$
\lim _{\lambda \rightarrow 0} \widehat{s}(\lambda)=0.5 \sqrt{2} \approx 0.71 \text { and } \lim _{\lambda \rightarrow 1} \widehat{s}(\lambda)=0
$$

and that

$$
\frac{d \widehat{s}(\lambda)}{d \lambda} \equiv-\frac{\frac{\partial \Psi^{j}(\lambda, s)}{\partial \lambda}}{\frac{\partial \Psi^{j}(\lambda, s)}{\partial s}}<0
$$

as $\frac{\partial \Psi^{j}}{\partial \lambda}<0$ and $\frac{\partial \Psi^{j}}{\partial s}<0 .{ }^{11}$ We also note that, for $s=0$

$$
\Psi^{j}(\lambda, s)=\frac{4 \alpha^{2}\left(269 \lambda^{4}+1715 \lambda^{3}+3599 \lambda^{2}+2760 \lambda+612\right)(\lambda-1)^{2}}{(7 \lambda+8)^{2}\left(26 \lambda^{2}+85 \lambda+54\right)^{2}}>0
$$

and, for $s=1$,

$$
\Psi^{j}(\lambda, s)=-\frac{2 \alpha^{2}\left(19 \lambda^{2}+42 \lambda+19\right)\left(5 \lambda^{2}+10 \lambda+1\right)}{(7 \lambda+9)^{2}(3 \lambda+5)^{2}}<0 .
$$

Therefore, when pollution is perfectly local, centrally set policy always yields greater damages; when pollution is perfectly transboundary, locally set policy always yields greater damages. When the two regions face the same productivity gap between sectors and the two production processes involve the same spillover rates, we then conclude that damages are always smaller under a central policy regime for $s>0.5 \sqrt{2}$; however, for $s<0.5 \sqrt{2}$, whether damages are greater or smaller under one regime or the other depends on $\lambda$. Specifically, as $\frac{d \widehat{s}(\lambda)}{d \lambda}<0$ and $\Psi^{j}(\lambda, s)>0$ for $s<\widehat{s}$, the larger $\lambda$ is, the lower the upper bound of the range of $s$ values over which damages under central taxes exceed damages under local taxes. Put differently, the larger the productivity gap between the two sectors, the more likely it is for a decentralized system to be preferable to a centralized system from an environmental point of view. In terms of Figure 4, damages are smaller with locally set taxes below (or to the left of) the $\widehat{s}$ curve.

Before we consider the implications of relaxing the assumption that $\rho_{s}=\rho_{\lambda}=1$, we look at the difference in environmental damages relative to the difference in taxes between the two regions. To be clear, we are interested in whether there exists consistency between the two differences whereby higher

\footnotetext{
${ }^{11}$ That $\frac{\partial \Psi^{j}}{\partial s}<0$ implies that $\Psi^{j}(\lambda, s)>0$ for $s<\widehat{s}$ and $\Psi^{j}(\lambda, s)<0$ for $s>\widehat{s}$. See appendix for more detail.
} 
environmental taxes under a particular policy regime correspond to lower environmental damages under the same regime or vice versa. To this end, we use (43) and (34), thus ignoring (33) which is always positive, and obtain

Proposition 7 For $s_{a}=s_{b}=s$ and $\lambda_{b}^{A}=\lambda_{a}^{B}=\lambda$, when the tax a region faces on the good it is more efficient at producing is larger under a central system than under a local system (i.e., $t_{i}^{j}>\widetilde{t}_{i}^{j}$ ), environmental damages are always smaller with central taxes. However, when the opposite holds true (i.e., $\left.t_{i}^{j}<\widetilde{t}_{i}^{j}\right)$, there exist s values for each productivity gap $\lambda$ such that environmental damages are greater under central policy.

Letting $\widehat{\widehat{s}}$ satisfy $T_{i}^{j}(\lambda, s) \equiv t_{i}^{j}-\widetilde{t}_{i}^{j}=0$, we have that $\lim _{\lambda \rightarrow 0} \widehat{\widehat{s}}(\lambda)=\lim _{\lambda \rightarrow 0} \widehat{s}(\lambda) \approx 0.71$ and $\lim _{\lambda \rightarrow 1} \widehat{\widehat{s}}(\lambda)=\lim _{\lambda \rightarrow 1} \widehat{s}(\lambda)=$ 0 and that

$$
\frac{\widehat{d \widehat{s}}(\lambda)}{d \lambda} \equiv-\frac{\frac{\partial T_{i}^{j}(\lambda, s)}{\partial \lambda}}{\frac{\partial T_{i}^{j}(\lambda, s)}{\partial s}}<0,
$$

as $\frac{\partial T_{i}^{j}}{\partial \lambda}>0$ and $\frac{\partial T_{i}^{j}}{\partial s}>0 .{ }^{12}$ We can then show that $\widehat{\widehat{s}}>\widehat{s}$ so that, for a given $\lambda$ and for $s<\widehat{\widehat{s}}$, central policy always involves lower environmental taxes but yields lower damages for values of $s \in(\widehat{s}, \widehat{\hat{s}})$ and greater damages for values of $s \in(0, \widehat{s})$. We illustrate the two possibilities in Figure 4 where $D_{1}$ denotes the area with lower taxes and damages under central policy and $D_{2}$ the area with lower taxes but greater damages under central policy.

As the environmental damage function is separable in pollutants emitted in different sectors, the level of pollution each sector contributes to is only dependent on the environmental policy in place in that sector both at home (own effect) as well as in the other region (cross effect). The own and cross effects of environmental policy work in opposite directions but the former is always larger in magnitude than the latter. Furthermore, if pollution is transboundary, the net effect of a switch from local governments to a central government (and thus a change in environmental policy) on the pollution level a region faces in a given sector is ultimately detemined by the size of the own and cross effects of its environmetal policy in that sector relative to the own and cross effects of the other region's environmental policy in the same sector. ${ }^{13}$ Given that the switch always triggers an increase in the environmental tax in the sector in which a region is less productive but either a decrease in the environmental tax in the more efficient sector or an increase that is however smaller than both the tax increase experienced by the same region in the less efficient sector $\left(0<d t_{i}^{j}<d t_{-i}^{j}\right)$ and the tax increase in the same sector experienced by the other region $\left(0<d t_{i}^{j}<d t_{i}^{-j}\right)$, the pollution level is more likely to fall in the less efficient sector. As summarized in

\footnotetext{
${ }^{12}$ That $\frac{\partial T_{i}^{j}}{\partial s}>0$ implies that $T_{i}^{j}(\lambda, s)>0$ for $s>\widehat{\widehat{s}}$ and $T_{i}^{j}(\lambda, s)<0$ for $s<\widehat{\widehat{s}}$. See appendix for more detail.

${ }^{13}$ Own and cross effects of environmental policy are given in Table 2a. Net effects of changes in environmental policy resulting from replacing a dentralized regime with a centralized regime are given in Table $2 \mathrm{~b}$.
} 
Tables $2 \mathrm{a}$ and $2 \mathrm{~b}$ and depicted in Figures $5 \mathrm{a}$ and $5 \mathrm{~b}$, an increase in $t_{-i}^{j}$ decreases the pollution level region $j$ faces in sector $-i$ when $t_{-i}^{-j}$ increases (that is, region $-j$, which has a comparative advantage in sector $-i$, experiences a tax increase in the same sector) for any degree of transboundary pollution (any $s$ ) and productivity gap $(\operatorname{any} \lambda)$, as well as when $t_{-i}^{-j}$ decreases provided that the productivity gap between the two regions is not excessively large. An increase in $t_{i}^{j}$ is however less likely to decrease the pollution level region $j$ faces in sector $i$ unless pollution spillovers are so significant that the effect from the pollution decrease in the other region dominates. At lower $s$ values, this dominance disappears and larger $\lambda$ values are then necessary to reduce the inter-regional trade effect in order to increase the relevance of the increase in $t_{i}^{j}$ which reduces region $j$ 's production of good $i$ and to decrease the relevance of the increase in $t_{i}^{-j}$ which increases region $j$ 's production of pollution of good $i$.

To clarify, let us consider the effects of tax changes from a shift to centralism in region $A$ which has a comparative advantage in sector $a$ and thus experiences a tax increase in sector $b\left(t_{b}^{A} \uparrow\right)$ and either a tax decrease or a smaller tax increase in sector $a\left(t_{a}^{A} \downarrow\right.$ or $t_{a}^{A} \uparrow$ but $\left.d t_{a}^{A}<d t_{b}^{A}\right)$. The increase in the tax in sector $b$ triggers a decrease in the production of good $b$ in region $A$ (own effect) and an increase in the production of good $b$ in region $B$ (cross effect). Given that, in absolute terms, the own effect dominates the cross effect and that the marginal contribution to pollution of region $B$ 's production does not exceed the marginal contribution to pollution of region $A$ 's production (that is, $s_{b} \leq 1$ ), the level of pollution region $A$ faces in sector $b$ decreases, other things being equal in region $B$. However, the shift to a central government also affects region $B$ 's taxes; as region $B$ has a comparative advantage in sector $b$, the tax it faces on good $b$ either decreases or increases by a smaller amount than region $A$ 's $\operatorname{tax}\left(t_{b}^{B} \downarrow\right.$ or $t_{b}^{B} \uparrow$ but $d t_{b}^{B}<d t_{b}^{A}$ ). If region $B$ 's tax increases, production of good $b$ falls in region $B$ (own effect) but increases in region $A$ (cross effect); with the own effect of the increase in $t_{b}^{A}$ dominating the cross effect of the increase in $t_{b}^{B}$, the cross effect of the former complementing the own effect of the latter, and $d t_{b}^{A}>d t_{a}^{A}$, region $A$ 's total pollution in sector $b$ always decreases.

On the other hand, if region $B$ 's tax decreases, production increases in region $B$ but decreases in region $A$; the own effect of the decrease in $t_{b}^{B}$ thus re-enforces the cross effect of the increase in $t_{b}^{A}$, provided that $s_{b}>0$, increasing region $A$ 's pollution, while the cross effect re-enforces the own effect of the increase in $t_{b}^{A}$ decreasing region $A$ 's pollution. As the own effect is always larger in the sector in which a region has a comparative advantage, it is possible, as long as $s_{b}>0$, for the overall positive effect on pollution (from own effect of decrease in $t_{b}^{B}$ and cross effect of increase in $t_{b}^{A}$ ) to more than offset the overall negative effect (from cross effect of decrease in $t_{b}^{B}$ and own effect of increase in $t_{b}^{A}$ ). It turns out that a sufficient, although 
not necessary, condition for the net effect on pollution to be negative is that some minimum productivity level be achieved in sector $b$ by region $A$. In fact, the more productive region $A$ is in sector $b$ (or the less inefficient region $A$ is relative to region $B$ ), the weaker the dominance of the own effect of the decrease in $t_{b}^{B}$ relative to the own effect of the increase in $t_{b}^{A}$. For very low values of $\lambda_{b}^{A}$, it is still possible for the net effect on pollution to be negative and we illustrate the possibility in Figure 5a as the two areas labelled $P_{1}$, with the area labelled $P_{2}$ then giving cases in which the net effect on pollution is positive.

For the net impact of shifting to centralism on the pollution level in the sector in which a region has a comparative advantage, we can sum up the above effects from the perspective of region $B$. So if $t_{b}^{B}$ increases, region $A$ 's contribution to region $B$ 's pollution in sector $b$ decreases as the own effect of the increase in $t_{b}^{A}$ (decrease in $x_{b}^{A}$ ) is stronger than the cross effect of the increase in $t_{b}^{B}$ (increase in $x_{b}^{A}$ ), at the margin, and $t_{b}^{A}$ increases by more than $t_{b}^{B}$. The relevance of this overall negative effect on pollution does depend on the degree of transboundary pollution: the more transboundary pollution is (the larger $s_{b}$ ), the more important the effect is. The direction of the change in region $B$ 's contribution to its own pollution in sector $b$ is however ambiguous as the own effect of the increase in $t_{b}^{B}$ (decrease in $x_{b}^{B}$ ) is stronger than the cross effect of the increase in $t_{b}^{A}$ (increase in $x_{b}^{B}$ ), at the margin, but $t_{b}^{B}$ increases by less than $t_{b}^{A}$. In spite of the ambiguity, we have that region $B$ 's pollution is always lower under a centralized policy system when region $A$ 's contribution to region $B$ 's pollution is substantial (that is, $s_{b}>1 / 3$ ); for $s_{b}<1 / 3$, it is still quite possible for region $B$ 's pollution to be lower under central taxes, as we illustrate in Figure 5b with the area labelled $P_{3}$, but not for every feasible value of $\lambda_{b}^{A}$. Specifically, for $s_{b}<1 / 3$, the impact of a reduction in region $A$ 's contribution to region $B$ 's pollution is less significant and a lower productivity gap between the two regions is then necessary for region $B$ 's contribution to its own pollution to decrease; at higher values of $\lambda_{b}^{A}$, the own effect of the increase in $t_{b}^{B}$ is less dominant relative to the cross effect of the increase in $t_{b}^{A}$ but the size of the increase in $t_{b}^{A}$ also falls relative to the size of the increase in $t_{b}^{B}$.

On the other hand, a decrease in $t_{b}^{B}$ re-enforces the positive effect that the increase in $t_{b}^{A}$ has on region $B$ 's production of good $b$ and, overall, causes region $B$ 's pollution in sector $b$ to always increase when region $A$ 's contribution is not substantial (or $s_{b}<1 / 3$ ); for $s_{b}>1 / 3$, it is still quite possible for region $B$ 's pollution to be higher under central taxes, as we illustrate in Figure 5b with the area labelled $P_{2}$, but not for every feasible value of $\lambda_{b}^{A}$. Specifically, for $s_{b}>1 / 3$, the impact of a reduction in region $A$ 's contribution to region $B$ 's pollution is more significant and a higher productivity gap between the two regions is then necessary for region $B$ 's contribution to its own pollution not only to increase but to increase by enough as to offset the negative effect of region $A$ 's contribution; as previously, at lower values of $\lambda_{b}^{A}$, the own effect 
of the increase in $t_{b}^{B}$ is more dominant relative to the cross effect of the increase in $t_{b}^{A}$, although the size of the increase in $t_{b}^{A}$ is larger relative to the size of the increase in $t_{b}^{B}$.

\subsubsection{Relaxing the Assumptions that $s_{a}=s_{b}=s$ and $\lambda_{b}^{A}=\lambda_{a}^{B}=\lambda$}

Using that $s_{i}=\rho_{s} s_{-i}$ and $\lambda_{-i}^{j}=\rho_{\lambda} \lambda_{i}^{-j}$ as we above define, we relax the assumptions that $s_{a}=s_{b}=s$ and $\lambda_{b}^{A}=\lambda_{a}^{B}=\lambda$ by considering the case in which $\rho_{s}<1$ and $\rho_{\lambda}<1$. Hence, we examine the difference in environmental damages both in region $j$ and in region $-j$. We begin with region $-j$ and obtain the following results:

$$
\begin{aligned}
& \frac{\partial\left(t_{i}^{-j}-\widetilde{t}_{i}^{-j}\right)}{\partial \rho_{s}}>0 \text { and } \frac{\partial\left(t_{i}^{-j}-\widetilde{t}_{i}^{-j}\right)}{\partial \rho_{\lambda}}=0, \\
& \frac{\partial\left(t_{-i}^{-j}-\widetilde{t}_{-i}^{-j}\right)}{\partial \rho_{s}}=0 \text { and } \frac{\partial\left(t_{-i}^{-j}-\widetilde{t}_{-i}^{-j}\right)}{\partial \rho_{\lambda}}>0,
\end{aligned}
$$

and

$$
\frac{\partial\left(\psi^{-j}-\widetilde{\psi}^{-j}\right)}{\partial \rho_{s}} \lessgtr 0 \text { and } \frac{\partial\left(\psi^{-j}-\widetilde{\psi}^{-j}\right)}{\partial \rho_{\lambda}}<0 .
$$

Similarly, for region $j$, we obtain the following effects:

$$
\begin{gathered}
\frac{\partial\left(t_{i}^{j}-\widetilde{t}_{i}^{j}\right)}{\partial \rho_{s}}>0 \quad \text { and } \quad \frac{\partial\left(t_{i}^{j}-\widetilde{t}_{i}^{j}\right)}{\partial \rho_{\lambda}}=0, \\
\frac{\partial\left(t_{-i}^{j}-\widetilde{t}_{-i}^{j}\right)}{\partial \rho_{s}}=0 \quad \text { and } \quad \frac{\partial\left(t_{-i}^{j}-\widetilde{t}_{-i}^{j}\right)}{\partial \rho_{\lambda}}>0,
\end{gathered}
$$

and

$$
\frac{\partial\left(\psi^{j}-\widetilde{\psi}^{j}\right)}{\partial \rho_{s}}<0 \text { and } \frac{\partial\left(\psi^{j}-\widetilde{\psi}^{j}\right)}{\partial \rho_{\lambda}} \lessgtr 0 .
$$

In spite of the above ambiguities in how a change in $\rho_{s}$ affects the difference in region $-j$ 's environmental damages between central and local policies, or $\psi^{-j}-\widetilde{\psi}^{-j}$, and a change in $\rho_{\lambda}$ affects the difference in region $j$ 's environmental damages between the two policies, or $\psi^{j}-\widetilde{\psi}^{j}$, we know, as we illustrate in Figure 6 , that $\frac{\partial\left(\psi^{-j}-\tilde{\psi}^{-j}\right)}{\partial \rho_{s}}<0$ for $\lambda_{i}^{-j}=\lambda \geqslant 0.09$ or $s_{i}=\rho_{s} s_{-i}=\rho_{s} s \geqslant 0.49$ and $\frac{\partial\left(\psi^{j}-\widetilde{\psi}^{j}\right)}{\partial \rho_{\lambda}}<0$ for $s_{-i}=s \geqslant 0.19$ or $\lambda_{-i}^{j}=\rho_{\lambda} \lambda_{i}^{-j}=\rho_{\lambda} \lambda \leqslant 0.50 .^{14}$

According to the above marginal effects, we have

Proposition 8 The less polluting good $i$ is relative to good $-i$ and/or the larger region $j$ 's comparative advantage relative to region - j's comparative advantage, the more likely it is for environmental damages to be higher under central policy in each of the two regions.

\footnotetext{
${ }^{14}$ We summarize the effects of changes in $\rho_{s}$ and $\rho_{\lambda}$ on taxes and environmental damages under central policy versus federal policy in Table 3 .
} 
A decrease in $\rho_{s}$ yields an increase in $\left(\psi^{j}-\widetilde{\psi}^{j}\right)$ and, provided that $\lambda$ is not sufficiently low, an increase in $\left(\psi^{-j}-\widetilde{\psi}^{-j}\right)$. Similarly, a decrease in $\rho_{\lambda}$ leads to an increase in $\left(\psi^{-j}-\widetilde{\psi}^{-j}\right)$ and, provided that $s$ is not sufficiently low, an increase in $\left(\psi^{j}-\widetilde{\psi}^{j}\right)$. As we illustrate in Figures 7 a to $7 \mathrm{~d}$, such changes correspond graphically to a rightward shifting of the zero-isovalue curves so that, for a given $s$, a larger $\lambda$ is necessary for the difference in environmental damages to be zero. The set of $s$ and $\lambda$ combinations above the zero isovalue curves which yield negative values for the differences in environmental damages thus gets smaller implying that central policy is less likely to result in lower environmental damages. While the effect of a decrease in $\rho_{s}$ is qualitatively the same as the effect of a decrease in $\rho_{\lambda}$, the former is stronger at high $s$ and low $\lambda$ values, especially on $\left(\psi^{j}-\widetilde{\psi}^{j}\right)$, and the latter at low $s$ and high $\lambda$ values, especially on $\left(\psi^{-j}-\widetilde{\psi}^{-j}\right)$.

In terms of the effects of changes in $\rho_{s}$ and $\rho_{\lambda}$ on taxes, we are particularly interested in the tax on the good a region is more efficient at producing (that is, good $i$ in region $j$ and $\operatorname{good}-i$ in region $-j$ ) under central policy versus federal policy. As the central tax on the good a region is less efficient at producing is always larger then the corresponding federal tax, the question of whether changes in $\rho_{s}$ and/or $\rho_{\lambda}$ impact the likelihood of central policy yielding higher or lower taxes is not applicable. Hence, when we consider the tax difference for the sector in which a region has a comparative advantage, we have

Proposition 9 The less polluting good $i$ is relative to good $-i$, the more likely it is for the tax on good $i$ in region $j$, which has a comparative advantage in its production, to be lower under central policy. The larger region $j$ 's comparative advantage relative to region $-j$ 's comparative advantage, the more likely it is for the tax on the good $-i$ in region $-j$, which has a comparative advantage in its production, to be lower under central policy.

A decrease in $\rho_{s}$ yields a decrease in $\left(t_{i}^{j}-\widetilde{t}_{i}^{j}\right)$ but no change in $\left(t_{-i}^{-j}-\widetilde{t}_{-i}^{-j}\right)$; a decrease in $\rho_{\lambda}$ leads instead to a decrease in $\left(t_{-i}^{-j}-\widetilde{t}_{-i}^{-j}\right)$ but no change in $\left(t_{i}^{j}-\widetilde{t}_{i}^{j}\right)$. As we illustrate in Figures $8 \mathrm{a}$ and $8 \mathrm{~b}$, such changes correspond graphically to a rightward shifting of the zero-isovalue curves so that, for a given $s$, a larger $\lambda$ is necessary for the difference in taxes to be zero. The set of $s$ and $\lambda$ combinations below the zero isovalue curves which yield negative values for the differences in taxes thus gets larger implying that central policy is more likely to result in lower taxes. While the effect of a decrease in $\rho_{s}$ on $\left(t_{i}^{j}-\widetilde{t}_{i}^{j}\right)$ is qualitatively the same as the effect of a decrease in $\rho_{\lambda}$ on $\left(t_{-i}^{-j}-\widetilde{t}_{-i}^{-j}\right)$, the former is stronger at high $s$ and low $\lambda$ values and the latter at low $s$ and high $\lambda$ values.

When $s_{i}<s_{-i}=s\left(\rho_{s}<1\right)$, the spillover effect is weaker in sector $i$ and the corresponding gap between the central tax and the local tax is thus smaller in region $-j$. What happens to the gap in region 
$j$ depends on whether the the difference between the two taxes is positive or negative when $\rho_{s}=1$ : if it is positive, the weakening in spillover effect amounts to a lower gap; if it is negative, it amounts to a larger gap (larger negative difference between the central tax and the local tax). As the spillover effect in a region is a positive function of the production level in the other region and as region $j$ produces more of good $i$ than region $-j$, a less transboundary pollution in sector $i$ involves a larger drop in the tax gap in region $-j$ than in region $j$, that is, $\frac{\partial\left(t_{i}^{-j}-\widetilde{t}_{i}^{-j}\right)}{\partial \rho_{s}}>\frac{\partial\left(t_{i}^{j}-\widetilde{t}_{i}^{j}\right)}{\partial \rho_{s}}>0$ (the comparison is meaningful when the central tax on good $i$ is higher than the local tax in the less productive region, that is, region $-j$ ).

Thus, a region that has a comparative advantage in the sector with greater spillovers (e.g., region $-j$ when $s_{-i}>s_{i}$ ) faces a lower tax gap between the two tax regimes in the less productive sector (e.g., sector i) and, provided that the central tax is larger than the local tax, a larger gap in the more productive sector. If, however, the central tax in the comparative advantage sector is lower than the local tax as a result of a strong inter-regional trade effect (or a large volume of trade with the other region), the region faces a lower tax gap in its efficient (and more polluting) sector. The lower central taxes in the sector with weaker spillovers amount to larger environmental damages under centralization so that the damage gap between the two tax systems is larger in both regions when the difference between central and local damages is positive and smaller when the difference is negative. If the central tax is instead lower than the local tax in the comparative advantage sector so that production is greater under centralization, lower spillovers in this sector have greater benefits in terms of a reduction in environmental damages in the region receiving the spillovers under centralization. It is then possible for these additional benefits to outweigh the additional costs of lower spillovers under a central tax regime (that is, a greater production increase through a greater tax reduction) when the inter-regional trade effect is strong and/or the spillover effect is very weak. A region that is less efficient in the sector with fewer spillovers may thus face a lower gap in environmental damages when it exports heavily from, and/or receives less pollution from, the other region (e.g., when $s_{i}<s_{-i}$, region $-j$ may end up with a lower damage gap between the two tax systems at low values of $\lambda_{i}^{-j}$ and/or $\left.s_{i}\right)$.

When $\lambda_{-i}^{j}<\lambda_{i}^{-j}=\lambda\left(\rho_{\lambda}<1\right)$, we have a stronger inter-regional trade effect in sector $-i$ which decreases the central tax in region $-j$ but increases it in region $j$, a weaker tax revenue effect which decreases the central tax in both regions, and a change in the inter-regional environmental effect which increases the central tax in region $-j$ if the own pollution effect dominates or decreases the central tax in region $j$ if the spillover effect dominates but has otherwise ambiguous effects. Overall, however, the gap between the central tax and the local tax on good $-i$ is always smaller in region $j$ and smaller in region 
$-j$ if the difference between the central and local taxes is positive when $\rho_{\lambda}=1$ but larger if the difference is negative when $\rho_{\lambda}=1$. Because of the different implications of a strengthening of the inter-regional trade effect for the tax gap depending on whether the sector is the more or less efficient one, a lower productivity gap in sector $-i$ involves a larger drop in the tax gap in region $-j$ than in region $j$, that is, $\frac{\partial\left(t_{-i}^{-j}-\widetilde{t}_{-i}^{-j}\right)}{\partial \rho_{\lambda}}>\frac{\partial\left(t_{-i}^{j}-\widetilde{t}_{-i}^{j}\right)}{\partial \rho_{\lambda}}>0$ (the comparison is meaningful when the central tax on good $-i$ is higher than the local tax in the more productive region, that is, region $-j$ ).

A region with a comparative advantage in the sector characterized by a larger productivity gap (e.g., region $-j$ when $1-\lambda_{-i}^{j}>1-\lambda_{i}^{-j}$ ) then faces a greater tax gap between the two tax regimes in the less productive sector (e.g., sector $i$ ) and, provided that the central tax is larger than the local tax, a lower gap in the more productive sector (e.g., sector $-i$ ). If, however, the central tax in the comparative advantage sector is lower than the local tax, the region faces a larger tax gap in its efficient sector. In terms of environmental damages, the productivity gap increase in one of the two sectors raises production in the more efficient region and decreases it in the less efficient region under either of the two tax systems. However, although overall damages may decrease under both centralization and decentralization if pollution is sufficiently transboundary, the presence of the inter-regional trade effect results in a larger production increase in the more efficient region under central taxes so that the damage gap between the two tax regimes increases in the more efficient region (e.g., $\psi^{-j}-\widetilde{\psi}^{-j}$ increases when $\lambda_{-i}^{j}$ decreases). In the less efficient region, environmental damages decrease under both tax systems as the production decrease (and thus pollution decrease) the region experiences due to the increase in productivity gap more than outweighs the production increase (and thus increase in pollution that spills over) in the more productive region.

When the productivity gap is larger, the damage decrease under centralization can be smaller or larger than the damage decrease under decentralization and, correspondingly, the damage gap can be larger or smaller. To understand the reason, we can think of the effect of a productivity gap change on production in the less efficient region as comprising a direct (positive) effect at given tax rates as captured in (11) which depends on the level of production and indirect (negative) effects through tax changes. Due to the interregional trade effect, a larger productivity gap triggers smaller decreases in central taxes which amount to weaker indirect effects and thus contribute to increasing the overall (positive) effect of a productivity gap change on production. However, also due to the inter-regional trade effect, the production level is smaller under central taxes and the resulting smaller direct effect thus contributes to decreasing the overall effect of a productivity gap change. For a given degree of transboundary pollution, the smaller the productivity gap is, the smaller the production gap between the two tax regimes is: the magnitude of the overall effect 
of a productivity gap change on production is then more likely to be determined by differences in indirect effects and production in the less productive region is thus more likely to decrease by more under central taxes in response to a productivity gap increase. For a given productivity gap, the less transboundary pollution is, the more relevant the inter-regional trade effect is: differences in indirect effects between the two tax regimes are then more important and production in the less productive region is thus more likely to decrease by more under central taxes in response to a productivity gap increase. Therefore, under centralization, the damage gap increases as the productivity gap increases when production in the less productive region falls by less but may decrease when it falls by more. ${ }^{15}$

If we take into account both the effects on environmental daamges and the effects on taxes, ${ }^{16}$ we find that, under central policy, lower taxes are less likely to be accompanied by smaller environmental damages whenever changes in $\rho_{s}$ or $\rho_{\lambda}$ have no impact on taxes. However, when central taxes decrease relative to federal taxes in response to a decrease in $\rho_{s}$ or in $\rho_{\lambda}$, smaller taxes are more likely to be accompanied by smaller environmental damages under central policy. In fact, the likelihood that region $j$ faces both a lower tax on good $i$ and lower environmental damages under central policy actually increases despite that region $j$ is less likely to face a higher tax on good $i$ under centralized policy, but is also less likely to enjoy a better environment when good $i$ has smaller pollution spillovers than good $-i$, as we illustrate in Figures 9a and 9b. Similarly, under central policy, region $-j$ is less likely to face a higher tax on good $-i$ (i.e., the good in which it has a comparative advantage) but is also less likely to experience lower environmental damages when its comparative advantage in sector $-i$ is not as strong as region $j$ 's comparative advantage in sector $i$; nevertheless, the effect on the tax dominates the effect on the environment so that, overall, region $-j$ is more likely to face both a lower tax on good $-i$ and lower environmental damages under central policy. ${ }^{17}$

\section{Conclusions}

In this paper, we examine the role of federalism versus centralism in the determination of environmental taxes. Comparing federalism and centralism, we are interested in the impact on both the individual taxes set on pollutants by the regional or central government(s) and the effect on total pollution damages in the country.

\footnotetext{
${ }^{15}$ That production in the less productive region fall by more under central taxes is a necessary but not sufficient condition for the damage gap to decrease in response to an increase in productivity gap.

${ }^{16}$ We are interested here in cases in which central taxes can be lower or higher than federal taxes depending on the values of $s$ and $\lambda$. Hence, we ignore instances in which central taxes are always higher than federal taxes, although decreases in $\rho_{s}$ and $\rho_{\lambda}$ reduce the extent to which the former exceed the latter. To be clear, we do not consider taxes on goods regions are less efficient at producing but which are affected by changes in $\rho_{s}$ and $\rho_{\lambda}$.

${ }^{17}$ We summarize these changes in Table 4.
} 
In the sector of regional comparative advantage, greater output generates increased pollution, which, at least without harmonization of central policy, results in taxes that are higher in the sector of the regional comparative advantage good when spillovers across regional boundaries and productivity gaps between sectors are symmetric. However, as spillovers of pollution decrease in the comparative advantage industry, the gap between the taxes on the two sectors decreases, and can potentially become negative. On the other hand, as the productivity gap in the production of the two goods increases (implying a larger comparative advantage), the gap between the taxes increases. Across regions, increased taxes in the comparative advantage industry results in lower local production and pollution but higher production and pollution in the other region.

As a result, independently of the degree of spillovers, we show that federalism results in weaker policy (lower taxes) than centralism on the good for which a region does not have a comparative advantage (that is, for the good that is less efficiently produced in a region). For the production of the more efficient good, federalism can lead to taxes that are higher or lower than centralized taxes, depending on the degree of inter-regional spillovers of pollution and the productivity gap between sectors. Despite the fact that centralism always leads to stronger policy in one of the goods, total environmental damages in a country can still be lower under federalism, particularly when spillovers are low or the productivity gap is large. In these cases, the environmental externality effect from pollution spillovers is dominated by a cross-regional competition effect. The centralized government lowers taxes on efficient good production to encourage inter-regional trade and increase the welfare of consumers (and to a lesser extent, producers). As this occurs, weaker centralized policy in the more efficient sector can possibly offset the stronger policy set in the less efficient sector and results in higher centralized damages.

Previous literature has suggested that lobbying and firm location competition under federalism can lead to a "race to the bottom," where regions push down environmental taxes (or weaken environmental standards) in an attempt to improve their position relative to other regions. Here, we have identified other effects which tends to weaken centralized policy, through the channels of multiple polluting goods and regional comparative advantage. If the gap between productivities in regional industries is large (and spillovers are not too high), federalism can actually lead to stronger (overall) environmental policy and lower environmental damages than centralism. 


\section{Appendix}

\subsection{Inter-regional Environmental Effect: Changes in $s$ and $\lambda$}

The inter-regional environmental effect depends on both $s$ according to

$$
\underbrace{\frac{x_{i}^{j}}{2} \frac{\partial x_{i}^{-j}}{\partial t_{i}^{j}}}_{M_{1}}+\underbrace{\left(\frac{x_{i}^{-j}}{2}+s_{i} x_{i}^{j}\right) \frac{\partial x_{i}^{j}}{\partial t_{i}^{j}}}_{M_{2}}
$$

and on $\lambda$ according to

$$
\underbrace{\frac{1}{2}}_{N_{1}} \underbrace{\left(\frac{\partial x_{i}^{-j}}{\partial \lambda_{i}^{-j}}+s_{i} \frac{\partial x_{i}^{j}}{\partial \lambda_{i}^{-j}}\right)}_{N_{2}} \underbrace{\left(\frac{\partial x_{i}^{-j}}{\partial t_{i}^{j}}+s_{i} \frac{\partial x_{i}^{j}}{\partial t_{i}^{j}}\right)}_{N_{3}}+\underbrace{\left(\frac{x_{i}^{-j}+s_{i} x_{i}^{j}}{2}\right)}_{N_{4}}(\underbrace{\left(\frac{\partial^{2} x_{i}^{-j}}{\partial t_{i}^{j} \partial \lambda_{i}^{-j}}+s_{i} \frac{\partial^{2} x_{i}^{j}}{\partial t_{i}^{j} \partial \lambda_{i}^{-j}}\right)}_{i} .
$$

In terms of the effect of a change in $s, M_{1}>0$ and represents the increase in the own pollution effect that provides the central government with an incentive to set lower taxes while $M_{2}<0$ and captures the increase in the spillover effect that provides the central government with an incentive to set higher taxes. Overall, however, the latter change dominates and an increase in $s$ thus induces the central government to opt for higher taxes than those set regionally in both sectors. For the sector in which a region has a comparative advantage (e.g., sector $i$ for region $j$ ), $M_{1}+M_{2}<0$ as $x_{i}^{j} \frac{\partial x_{i}^{-j}}{\partial t_{i}^{j}}+x_{i}^{-j} \frac{\partial x_{i}^{j}}{\partial t_{i}^{j}}=$ $-\frac{2 \lambda_{i}^{-j}\left[\left(\alpha+2 t_{i}^{j}-3 t_{i}^{-j}\right)+\lambda_{i}^{-j}\left(\alpha+t_{i}^{j}-2 t_{i}^{-j}\right)\right]}{\left(3+\lambda_{i}^{-j}\right)^{2}}<0$; for the other sector (e.g., sector $-i$ for region $j$ ), that $M_{1}+M_{2}<0$ is even more straightforward as $x_{-i}^{-j}>x_{-i}^{j}$ and $\left|\frac{\partial x_{-i}^{j}}{\partial t_{-i}^{j}}\right|>\frac{\partial x_{-i}^{-j}}{\partial t_{-i}^{j}}$ so that $x_{-i}^{j} \frac{\partial x_{-i}^{-j}}{\partial t_{-i}^{j}}+x_{-i}^{-j} \frac{\partial x_{-i}^{j}}{\partial t_{-i}^{j}}<0$.

In terms of the effect of a change in $\lambda$, if the own pollution effect dominates, $N_{2}>0$; furthermore, assuming that sector $i$ is the one in which region $-j$ does not have a comparative advantage, we know, from (11), that $N_{1}=\frac{\left(3-s_{i}\right) x_{i}^{-j}}{\lambda_{i}^{-j}\left(3+\lambda_{i}^{-j}\right)}>0$ and, from (8), that $N_{4}=\frac{3-s_{i}}{\left(3+\lambda_{i}^{-j}\right)^{2}}>0$. We then have that an increase in $\lambda_{i}^{-j}$ strengthens the central government's incentive to reduce the environmental tax on the good in which a region has a comparative advantage (e.g., good $i$ in region $j$ ). However, when we consider the inter-regional environmental effect in sector $-i$, that is, the sector in which region $-j$ has a comparative advantage, if the spillover effect dominates, $N_{2}=\frac{\lambda_{-i}^{j}\left(1-3 s_{-i}\right)}{\left(3+\lambda_{-i}^{j}\right)}<0$ so that $N_{1}=-\frac{\left(1-3 s_{-i}\right) x_{-i}^{j}}{\lambda_{-i}^{j}\left(3+\lambda_{-i}^{j}\right)}>0$ and $N_{4}=\frac{3\left(1-3 s_{-i}\right)}{\left(3+\lambda_{-i}^{j}\right)^{2}}<0$. We then have that an increase in $\lambda_{-i}^{j}$ strengthens the central government's incentive to increase the environmental tax on the good in which a region does not have a comparative advantage (e.g., good $-i$ in region $j$ ). 


\subsection{Proposition 1: Effects of $s$ and $\lambda$ on Centrally Set Taxes}

By partially differentiating (18) and (19) with respect to $s_{i}$, we obtain

$$
\frac{\partial t_{i}^{j}}{\partial s_{i}}=\frac{8 \alpha\left\{3 s_{i}+\left[2\left(1-s_{i}\right)^{2}\left(1+s_{i}\right)+\left(3+s_{i}^{3}\right)\right] \lambda_{i}^{-j}+\left[\left(1-s_{i}\right)\left(4+3 s_{i}^{3}\right)+s_{i}^{5}\right]\left(\lambda_{i}^{-j}\right)^{2}\right\}}{\left\{2\left(4+s_{i}^{2}\right)+\left[\left(1+s_{i}^{2}\right)^{2}+2\left(3-2 s_{i}\right)\right] \lambda_{i}^{-j}\right\}^{2}}
$$

and

$$
\begin{aligned}
\frac{\partial t_{i}^{-j}}{\partial s_{i}}= & \frac{4 \alpha\left\{2\left(4-s_{i}^{2}\right)+\left[2\left(2-s_{i}^{2}\right)+3\left(8-3 s_{i}\right)\left(1+s_{i}^{3}\right)\right] \lambda_{i}^{-j}\right\}}{\left\{2\left(4+s_{i}^{2}\right)+\left[\left(1+s_{i}^{2}\right)^{2}+2\left(3-2 s_{i}\right)\right] \lambda_{i}^{-j}\right\}^{2}}+ \\
& +\frac{4 \alpha\left[3\left(1-s_{i}\right)\left(1+s_{i}^{3}\right)+s_{i}^{3}\left(1+s_{i}^{2}\right)\right]\left(\lambda_{i}^{-j}\right)^{2}}{\left\{2\left(4+s_{i}^{2}\right)+\left[\left(1+s_{i}^{2}\right)^{2}+2\left(3-2 s_{i}\right)\right] \lambda_{i}^{-j}\right\}^{2}}
\end{aligned}
$$

both of which are positive; hence, the greater the spillover effects of production, the more heavily production is taxed. Similarly, by partially differentiating (18) and (19) with respect to $\lambda_{i}^{-j}$, we have

$$
\frac{\partial t_{i}^{j}}{\partial \lambda_{i}^{-j}}=-\frac{2 \alpha\left(1-6 s_{i}+s_{i}^{2}\right)\left(3-2 s_{i}+s_{i}^{2}\right)}{\left\{2\left(4+s_{i}^{2}\right)+\left[\left(1+s_{i}^{2}\right)^{2}+2\left(3-2 s_{i}\right)\right] \lambda_{i}^{-j}\right\}^{2}}
$$

which is negative for $s_{i} \in[0,3-2 \sqrt{2})$ and positive for $s_{i} \in(3-2 \sqrt{2}, 1]$, and

$$
\frac{\partial t_{i}^{-j}}{\partial \lambda_{i}^{-j}}=\frac{2 \alpha\left(3-2 s_{i}+s_{i}^{2}\right)\left(4-2 s_{i}+s_{i}^{2}+s_{i}^{4}\right)}{\left\{2\left(4+s_{i}^{2}\right)+\left[\left(1+s_{i}^{2}\right)^{2}+2\left(3-2 s_{i}\right)\right] \lambda_{i}^{-j}\right\}^{2}}
$$

which is always positive; hence, as the productivity gap between the two regions narrows, the tax in the less efficient region always increases while the tax in the more efficient region increases provided that $s_{i}>0.1716$.

\subsection{Harmonized versus Unharmonized Taxes}

We can write differences between the unharmonized taxes given in (18) and (19) and the harmonized taxes given in (27) and (28) as

$$
t_{i}^{j}-t_{i}^{h}=\frac{\alpha \lambda_{i}^{-j}\left(1-\lambda_{i}^{-j}\right)\left(s_{i}-1\right)^{2}\left(3 s_{i}^{2} \lambda_{i}^{-j}-s_{i}^{2}-2 s_{i} \lambda_{i}^{-j}+6 s_{i}+5 \lambda_{i}^{-j}+5\right)}{\left[4+s_{i}^{2}+\lambda_{i}^{-j}\left(4+s_{i}^{2} \lambda_{i}^{-j}+4 s_{i}+2 \lambda_{i}^{-j}\right)\right]\left\{2\left(4+s_{i}^{2}\right)+\left[\left(1+s_{i}^{2}\right)^{2}+2\left(3-2 s_{i}\right)\right] \lambda_{i}^{-j}\right\}}>0
$$

and

$$
t_{i}^{-j}-t_{i}^{h}=\frac{\alpha\left(1-\lambda_{i}^{-j}\right)\left(s_{i}-1\right)^{2}\left\{\lambda_{i}^{-j}\left[-3-2 s_{i}-s_{i}^{2}+\lambda_{i}^{-j}\left(1-s_{i}\right)^{2}\right]\right\}}{\left[4+s_{i}^{2}+\lambda_{i}^{-j}\left(4+s_{i}^{2} \lambda_{i}^{-j}+4 s_{i}+2 \lambda_{i}^{-j}\right)\right]\left\{2\left(4+s_{i}^{2}\right)+\left[\left(1+s_{i}^{2}\right)^{2}+2\left(3-2 s_{i}\right)\right] \lambda_{i}^{-j}\right\}}<0
$$


for $i=a, b$ and $j=A, B$ with $j=A(-j=B)$ when $i=a$ and $j=B(-j=A)$ when $i=b$. Under harmonization, the less efficient region subsidizes the more efficient region; however, upon inspection of the two differences, we find that the tax increase in the less efficient region exceeds the tax decrease in the more efficient region unless pollution is a pure public bad. We can in fact write the difference between the absolute values of the two tax changes as

$t_{i}^{j}-t_{i}^{h}-\left|t_{i}^{-j}-t_{i}^{h}\right|=\frac{2 \alpha\left(\lambda_{i}^{-j}-1\right)^{2}\left(s_{i}-1\right)^{2}\left(2 s_{i} \lambda_{i}^{-j}-2 s_{i}^{2} \lambda_{i}^{-j}-3 \lambda_{i}^{-j}-s_{i}^{2}-4\right)}{\left[4+s_{i}^{2}+\lambda_{i}^{-j}\left(4+s_{i}^{2} \lambda_{i}^{-j}+4 s_{i}+2 \lambda_{i}^{-j}\right)\right]\left\{2\left(4+s_{i}^{2}\right)+\left[\left(1+s_{i}^{2}\right)^{2}+2\left(3-2 s_{i}\right)\right] \lambda_{i}^{-j}\right\}}$,

which is always negative provided that $s_{i}<1$ and zero if $s_{i}=1$, that is, pollution is perfectly transboundary.

In terms of emissions $(E)$, the difference under unharmonized and harmonized taxes $(\Delta E)$ is equal to

$$
\Delta E_{i}^{j}=\frac{2 \alpha\left(1-\lambda_{i}^{-j}\right)\left(s_{i}-1\right)^{3}\left\{\lambda_{i}^{-j}\left[3+s_{i}+s_{i}^{2}+\lambda_{i}^{-j}\left(2+s_{i}\right)\right]\right\}}{\left[4+s_{i}^{2}+\lambda_{i}^{-j}\left(4+s_{i}^{2} \lambda_{i}^{-j}+4 s_{i}+2 \lambda_{i}^{-j}\right)\right]\left\{2\left(4+s_{i}^{2}\right)+\left[\left(1+s_{i}^{2}\right)^{2}+2\left(3-2 s_{i}\right)\right] \lambda_{i}^{-j}\right\}}<0
$$

for the sector in which a region has a comparative advantage (i.e., sector $i$ in region $j$ ) and

$$
\Delta E_{i}^{-j}=\frac{2 \alpha\left(\lambda_{i}^{-j}-1\right)\left(s_{i}-1\right)^{3}\left\{\lambda_{i}^{-j}\left[4+s_{i}+\lambda_{i}^{-j}\left(1+s_{i}+s_{i}^{2}\right)\right]\right\}}{\left[4+s_{i}^{2}+\lambda_{i}^{-j}\left(4+s_{i}^{2} \lambda_{i}^{-j}+4 s_{i}+2 \lambda_{i}^{-j}\right)\right]\left\{2\left(4+s_{i}^{2}\right)+\left[\left(1+s_{i}^{2}\right)^{2}+2\left(3-2 s_{i}\right)\right] \lambda_{i}^{-j}\right\}}>0 .
$$

for the sector in which a region does not have a comparative advantage (i.e., sector $i$ in region $-j$ ), with $\Delta E_{i}^{-j}-\left|\Delta E_{i}^{j}\right|>0$. When $s_{i}=s_{-i}$ and $\lambda_{i}^{-j}=\lambda_{-i}^{j}, \Delta E_{i}^{j}=\Delta E_{-i}^{-j}$ and $\Delta E_{-i}^{j}=\Delta E_{i}^{-j}$ so that $\left|\Delta E_{i}^{j}\right|<\Delta E_{-i}^{j}$ which says that the additional pollution harmonization contributes to in the comparative advantage sector outweights the lower pollution it yields in the less efficient sector and environmental damages are thus more significant under harmonized taxes. As

$$
\frac{\partial \Delta E_{-i}^{j}}{\partial s_{i}}=\frac{\partial \Delta E_{-i}^{-j}}{\partial s_{i}}=0 \text { and } \frac{\partial \Delta E_{i}^{-j}}{\partial s_{i}}<0<\frac{\partial \Delta E_{i}^{j}}{\partial s_{i}}
$$

we have that, the more transboundary pollution in sector $i$ is, the less (more) environmentally friendly unharmonized policy is for the region which has (does not have) a comparative advantage in sector $i$. If $s_{i}>s_{-i}$, but $\lambda_{i}^{-j}=\lambda_{-i}^{j}$, it is then possible for region $j$ to be better off, from an environmental standpoint, under harmonization.

What happens if $\lambda_{i}^{-j}>\lambda_{-i}^{j}$ but $s_{i}=s_{-i}$ is more complicated because of offsetting effects. In fact, letting $\Delta x_{i}^{j}$ and $\Delta x_{i}^{-j}$ denote the production differences in sector $i$, and, correspondingly, $\Delta t_{i}^{j}$ and $\Delta t_{i}^{-j}$ the tax differences, between unharmonized and harmonized policy regimes in regions $j$ and $-j$, we have

$$
\frac{\partial \Delta x_{i}^{j}}{\partial \lambda_{i}^{-j}}=\underbrace{\frac{1}{\left(3+\lambda_{i}^{-j}\right)^{2}}\left(3 \Delta t_{i}^{-j}-\Delta t_{i}^{j}\right)}_{<0}+\underbrace{\left(\frac{1}{3+\lambda_{i}^{-j}}\right)\left[\lambda_{i}^{-j} \frac{\partial \Delta t_{i}^{-j}}{\partial \lambda_{i}^{-j}}-\left(2+\lambda_{i}^{-j}\right) \frac{\partial \Delta t_{i}^{j}}{\partial \lambda_{i}^{-j}}\right]}_{>0}
$$


and

$$
\frac{\partial \Delta x_{i}^{-j}}{\partial \lambda_{i}^{-j}}=\underbrace{\frac{3}{\left(3+\lambda_{i}^{-j}\right)^{2}}\left(\Delta t_{i}^{j}-3 \Delta t_{i}^{-j}\right)}_{>0}+\underbrace{\left(\frac{\lambda_{i}^{-j}}{3+\lambda_{i}^{-j}}\right)\left(\frac{\partial \Delta t_{i}^{j}}{\partial \lambda_{i}^{-j}}-3 \frac{\partial \Delta t_{i}^{-j}}{\partial \lambda_{i}^{-j}}\right)}_{<0},
$$

where $\Delta t_{i}^{j}>0, \Delta t_{i}^{-j}<0, \frac{\partial \Delta t_{i}^{j}}{\partial \lambda_{i}^{-j}}<0$, and $\frac{\partial \Delta t_{i}^{-j}}{\partial \lambda_{i}^{-j}}>0$. The larger $\lambda_{i}^{-j}$ is, the smaller the direct effects through the tax differences and the larger the indirect effects through the changes in the tax differences; hence, as

$$
\frac{\partial \Delta E_{i}^{j}}{\partial \lambda_{i}^{-j}}=\frac{\partial \Delta x_{i}^{j}}{\partial \lambda_{i}^{-j}}+s_{i} \frac{\partial \Delta x_{i}^{-j}}{\partial \lambda_{i}^{-j}} \quad \text { and } \quad \frac{\partial \Delta E_{i}^{-j}}{\partial \lambda_{i}^{-j}}=\frac{\partial \Delta x_{i}^{-j}}{\partial \lambda_{i}^{-j}}+s_{i} \frac{\partial \Delta x_{i}^{j}}{\partial \lambda_{i}^{-j}},
$$

the pollution gap tends to increase (decrease) in region $j$ (region $-j$ ) at high values of $\lambda_{i}^{-j}$ and, the more transboundary pollution in sector $i$ is (that is, the higher $s_{i}$ is), the lower (higher) the values of $\lambda_{i}^{-j}$ that are required for the pollution gap to increase (decrease) in region $j$ (region $-j$ ).

\subsection{Effects of $s$ and $\lambda$ on Locally Set Taxes}

By partially differentiating (30) and (31) with respect to $s_{i}$, we obtain

$$
\frac{\partial \widetilde{t}_{i}^{j}}{\partial s_{i}}=-\frac{2 \alpha \lambda_{i}^{-j}\left[\gamma_{1}\left(\lambda_{i}^{-j}\right)^{3}+\gamma_{2}\left(\lambda_{i}^{-j}\right)^{2}+\gamma_{3} \lambda_{i}^{-j}+\gamma_{4}\right]}{\widetilde{n}_{i}^{2}}
$$

and

$$
\frac{\partial \widetilde{t}_{i}^{-j}}{\partial s_{i}}=-\frac{2 \alpha \lambda_{i}^{-j}\left[\delta_{1}\left(\lambda_{i}^{-j}\right)^{4}+\delta_{2}\left(\lambda_{i}^{-j}\right)^{3}+\delta_{3}\left(\lambda_{i}^{-j}\right)^{2}+\delta_{4} \lambda_{i}^{-j}+\delta_{5}\right]}{\widetilde{n}_{i}^{2}}
$$

where

$$
\begin{aligned}
& \gamma_{1}=-58+238 s_{i}-203 s_{i}^{2}+116 s_{i}^{3}-47 s_{i}^{4}+10 s_{i}^{5} \\
& \gamma_{2}=-321+938 s_{i}-666 s_{i}^{2}+304 s_{i}^{3}-59 s_{i}^{4}+2 s_{i}^{5} \\
& \gamma_{3}=-659+1044 s_{i}-535 s_{i}^{2}+132 s_{i}^{3}-2 s_{i}^{4} \\
& \gamma_{4}=-414+238 s_{i}-108 s_{i}^{2}, \\
& \delta_{1}=-18+90 s_{i}-111 s_{i}^{2}+68 s_{i}^{3}-23 s_{i}^{4}+4 s_{i}^{5} \\
& \delta_{2}=-129+454 s_{i}-490 s_{i}^{2}+244 s_{i}^{3}-51 s_{i}^{4}+4 s_{i}^{5} \\
& \delta_{3}=-407+902 s_{i}-663 s_{i}^{2}+216 s_{i}^{3}-30 s_{i}^{4}+4 s_{i}^{5} \\
& \delta_{4}=-574+846 s_{i}-248 s_{i}^{2}+24 s_{i}^{3}-4 s_{i}^{4} \\
& \delta_{5}=-324+216 s_{i},
\end{aligned}
$$


and $\widetilde{n}_{i}$ is given in (32). Noting that $\gamma_{k}($ for $k=1, \ldots, 4)$ and $\delta_{k}$ (for $\left.k=1, \ldots, 5\right)$ are increasing functions of $s_{i}$ and that, for $s_{i}=1$,

$$
\gamma_{1}\left(\lambda_{i}^{-j}\right)^{3}+\gamma_{2}\left(\lambda_{i}^{-j}\right)^{2}+\gamma_{3} \lambda_{i}^{-j}+\gamma_{4}=2\left(\lambda_{i}^{-j}-1\right)\left(4 \lambda_{i}^{-j}+13\right)\left(7 \lambda_{i}^{-j}+9\right)<0
$$

and

$\delta_{1}\left(\lambda_{i}^{-j}\right)^{4}+\delta_{2}\left(\lambda_{i}^{-j}\right)^{3}+\delta_{3}\left(\lambda_{i}^{-j}\right)^{2}+\delta_{4} \lambda_{i}^{-j}+\delta_{5}=2\left(\lambda_{i}^{-j}-1\right)\left[5\left(\lambda_{i}^{-j}\right)^{3}+21\left(\lambda_{i}^{-j}\right)^{2}+32 \lambda_{i}^{-j}+54\right]<0$

we have that $\frac{\partial \widetilde{t}_{i}^{j}}{\partial s_{i}}$ and $\frac{\partial \widetilde{t}_{i}^{-j}}{\partial s_{i}}$ are positive over the entire range of feasible values of $s_{i}$.

When we partially differentiate (30) and (31) with respect to $\lambda_{i}^{-j}$, we obtain

$$
\frac{\partial \widetilde{t}_{i}^{j}}{\partial \lambda_{i}^{-j}}=-\frac{2 \alpha\left[\vartheta_{1}\left(\lambda_{i}^{-j}\right)^{2}+\vartheta_{2} \lambda_{i}^{-j}+\vartheta_{3}\right]}{\widetilde{n}_{i}^{2}}
$$

and

$$
\frac{\partial \widetilde{t}_{i}^{-j}}{\partial \lambda_{i}^{-j}}=-\frac{2 \alpha\left[\rho_{1}\left(\lambda_{i}^{-j}\right)^{2}+\rho_{2} \lambda_{i}^{-j}+\rho_{3}\right]}{\widetilde{n}_{i}^{2}}
$$

where

$$
\begin{aligned}
& \vartheta_{1}=-27-25 s_{i}+265 s_{i}^{2}-160 s_{i}^{3}+53 s_{i}^{4}-9 s_{i}^{5}+s_{i}^{6} \\
& \vartheta_{2}=252-396 s_{i}+504 s_{i}^{2}-144 s_{i}^{3}+36 s_{i}^{4} \\
& \vartheta_{3}=468-414 s_{i}+144 s_{i}^{2}-36 s_{i}^{3}
\end{aligned}
$$

and

$$
\begin{aligned}
& \rho_{1}=-185+239 s_{i}-45 s_{i}^{2}-80 s_{i}^{3}+60 s_{i}^{4}-17 s_{i}^{5}+2 s_{i}^{6} \\
& \rho_{2}=-752+700 s_{i}-138 s_{i}^{2}-156 s_{i}^{3}+102 s_{i}^{4}-28 s_{i}^{5}+4 s_{i}^{6} \\
& \rho_{3}=-845+446 s_{i}-49 s_{i}^{2}-44 s_{i}^{3}+22 s_{i}^{4}-4 s_{i}^{5} .
\end{aligned}
$$

As $\vartheta_{1}$ is negative for $0<s_{i}<0.43$ but $\vartheta_{3}$ and $\vartheta_{2}$ are positive for $s_{i} \in[0,1]$ and $\vartheta_{2}>\vartheta_{1}$, we conclude that $\frac{\partial \widetilde{t}_{i}^{j}}{\partial \lambda_{i}^{-j}}<0$; also, $\rho_{1}, \rho_{2}$, and $\rho_{3}$ are negative for $s_{i} \in[0,1]$ so that $\frac{\partial \tilde{t}_{i}^{-j}}{\partial \lambda_{i}^{-j}}>0$.

Using the above results and the fact that cross-sectoral effects are absent (that is, pollution spillovers and productivity gap in sector $-i$ do not affect taxes in sector $i$ ), we derive that

$$
\begin{gathered}
\frac{\partial\left(\widetilde{t}_{i}^{j}-\widetilde{t}_{-i}^{j}\right)}{\partial s_{i}}=\frac{\partial \widetilde{t}_{i}^{j}}{\partial s_{i}}>0, \\
\frac{\partial\left(\widetilde{t}_{i}^{j}-\widetilde{t}_{-i}^{j}\right)}{\partial s_{-i}}=-\frac{\partial \widetilde{t}_{-i}^{j}}{\partial s_{-i}}<0,
\end{gathered}
$$




$$
\frac{\partial\left(\widetilde{t}_{i}^{j}-\widetilde{t}_{-i}^{j}\right)}{\partial \lambda_{i}^{-j}}=\frac{\partial \widetilde{t}_{i}^{j}}{\partial \lambda_{i}^{-j}}<0
$$

and

$$
\frac{\partial\left(\widetilde{t}_{i}^{j}-\widetilde{t}_{-i}^{j}\right)}{\partial \lambda_{-i}^{j}}=-\frac{\partial \widetilde{t}_{-i}^{j}}{\partial \lambda_{-i}^{j}}<0
$$

\subsection{Comparing Environmental Damages}

To determine the effect of a change in $\lambda$ on the threshold values of $s$ such that $\Psi^{j}(\lambda, s) \equiv \psi^{j}-\widetilde{\psi}^{j}=0$ and $T_{i}^{j}(\lambda, s) \equiv t_{i}^{j}-\widetilde{t}_{i}^{j}=0$ (namely, $\widehat{s}$ and $\widehat{\widehat{s}}$ ), we obtain the partial derivatives of $\Psi^{j}(\lambda, s)$ and $T_{i}^{j}(\lambda, s)$ with respect to $s$ and $\lambda$ as

$$
\begin{gathered}
\frac{\partial \Psi^{j}(\lambda, s)}{\partial s}=\frac{4 \alpha^{2}}{[F(s, \lambda) H(s, \lambda)]^{3}}\left[G^{\Psi}(s)+\sum_{k=1}^{9} G_{k}^{\Psi}(s) \lambda^{k}\right]<0, \\
\frac{\partial \Psi^{j}(\lambda, s)}{\partial \lambda}=\frac{4 \alpha^{2}}{[F(s, \lambda) H(s, \lambda)]^{3}}\left[\sum_{k=0}^{3} B_{k}^{\Psi}(s) \lambda^{k}+\sum_{k=4}^{9} A_{k}^{\Psi}(s) \lambda^{k}\right]<0, \\
\frac{\partial T_{i}^{j}(\lambda, s)}{\partial s}=\frac{2 \alpha}{[F(s, \lambda) H(s, \lambda)]^{2}}\left[G^{T}(s)+\sum_{k=1}^{6} G_{k}^{T}(s) \lambda^{k}\right]>0,
\end{gathered}
$$

and

$$
\frac{\partial T_{i}^{j}(\lambda, s)}{\partial \lambda}=\frac{2 \alpha}{[F(s, \lambda) H(s, \lambda)]^{2}}\left[\sum_{k=0}^{2} B_{k}^{T}(s) \lambda^{k}+\sum_{k=3}^{4} A_{k}^{T}(s) \lambda^{k}\right]>0,
$$

where $G^{l}(s) \geq 0, G_{k}^{l}(s)>0, B_{k}^{l}(s)>0$, and $A_{k}^{l}(s) \gtrless 0$, for $l=\Psi, T$, all of which are polynomial functions of $s$,

$$
F(s, \lambda)=\left(s^{4}-4 s^{3}-s^{2}+16 s-26\right) \lambda^{2}+\left(-2 s^{3}+5 s^{2}+22 s-85\right) \lambda-54<0,
$$

and

$$
H(s, \lambda)=\left(s^{4}+2 s^{2}-4 s+7\right) \lambda+2 s^{2}+8>0 .
$$

As $\lambda \in(0,1], \sum_{k=0}^{k_{1}} B_{k}^{l}(s) \lambda^{k}>\lambda^{k_{1}} \sum_{k=0}^{k_{1}} B_{k}^{l}(s)$ and $\left|\sum_{k=k_{1}+1}^{k_{2}} A_{k}^{l}(s) \lambda^{k}\right|<\lambda^{k_{1}}\left|\sum_{k=k_{1}+1}^{k_{2}} A_{k}^{l}(s)\right|$; noting that $\sum_{k=0}^{k_{1}} B_{k}^{l}(s)+\sum_{k=k_{1}+1}^{k_{2}} A_{k}^{l}(s)>0$, we have that

$$
\left[\sum_{k=0}^{k_{1}} B_{k}^{l}(s) \lambda^{k}+\sum_{k=k_{1}+1}^{k_{2}} A_{k}^{l}(s) \lambda^{k}\right]>\lambda^{k_{1}}\left[\sum_{k=0}^{k_{1}} B_{k}^{l}(s)+\sum_{k=k_{1}+1}^{k_{2}} A_{k}^{l}(s)\right]>0,
$$

where $k_{1}=3$ and $k_{2}=9$ when $l=\Psi$ and $k_{1}=2$ and $k_{2}=4$ when $l=T$. Hence,

$$
\frac{d \widehat{s}(\lambda)}{d \lambda} \equiv-\frac{\frac{\partial \Psi^{j}(\lambda, s)}{\partial \lambda}}{\frac{\partial \Psi^{j}(\lambda, s)}{\partial s}}<0 \quad \text { and } \quad \frac{d \widehat{s}(\lambda)}{d \lambda} \equiv-\frac{\frac{\partial T_{i}^{j}(\lambda, s)}{\partial \lambda}}{\frac{\partial T_{i}^{j}(\lambda, s)}{\partial s}}<0
$$


To show that $\widehat{s}<\widehat{\widehat{s}}$, we totally differentiate the damage function of region $j$ and obtain

$$
d \psi^{j} \equiv \Psi^{j} \equiv \psi^{j}-\widetilde{\psi}^{j}=2 \sum_{i=a, b}\left(x_{i}^{j}+s_{i} x_{i}^{-j}\right)\left(d x_{i}^{j}+s_{i} d x_{i}^{-j}\right)
$$

where

$$
d x_{i}^{j}=\left(\frac{1}{3+\lambda_{i}^{-j}}\right)\left[\lambda_{i}^{-j} d t_{i}^{-j}-\left(2+\lambda_{i}^{-j}\right) d t_{i}^{j}\right] \quad \text { and } \quad d x_{i}^{-j}=\left(\frac{\lambda_{i}^{-j}}{3+\lambda_{i}^{-j}}\right)\left[d t_{i}^{j}-3 d t_{i}^{-j}\right]
$$

for $j=A(B)$ and $-j=B(A)$ when $i=a(b)$. Using that $d t_{i}^{-j}=d t_{-i}^{j}=d t>0$ and $d t_{i}^{j}=d t_{-i}^{-j}$ when $s_{i}=s_{-i}=s$ and $\lambda_{i}^{-j}=\lambda_{-i}^{j}=\lambda$, so that $x_{i}^{j}=x_{-i}^{-j}=x^{*}$ and $x_{i}^{-j}=x_{-i}^{j}=x$, and setting $d t_{i}^{j}=0$, the total change in environmental damages when we move from a decentralized system to a centralized system reduces to

$$
d \psi^{j}=\frac{2 \lambda}{3+\lambda}\left[\left(s^{2}-6 s+1\right) x^{*}+\left(-3 s^{2}+2 s-3\right) x\right] d t
$$

where

$$
x^{*}=\frac{2\left[2+\lambda(1-s)^{2}\right]}{2\left(4+s^{2}\right)+\left[\left(1+s^{2}\right)^{2}+2(3-2 s)\right] \lambda} \quad \text { and } \quad x=\frac{2\left(s^{2}-2 s+3\right) \lambda}{2\left(4+s^{2}\right)+\left[\left(1+s^{2}\right)^{2}+2(3-2 s)\right] \lambda} .
$$

Upon substitution for $x^{*}$ and $x$, we then get

$$
d \psi^{j}=-\frac{4 \alpha \lambda}{3+\lambda}\left\{\frac{2 \lambda\left(s^{4}+4\right)+2 s[2(3-\lambda)-s(1-\lambda)]-2}{2\left(4+s^{2}\right)+\left[\left(1+s^{2}\right)^{2}+2(3-2 s)\right] \lambda}\right\} d t
$$

which is negative for $s=\widehat{\widehat{s}}$, that is, for values of $s$ such that $T_{i}^{j}(\lambda, s)=0$; as $\frac{\partial \Psi^{j}(\lambda, s)}{\partial s}<0$, we thus have that $\widehat{s}<\widehat{\widehat{s}}$.

\section{References}

[1] Aidt, T.S. (1998), "Political internalization of economic externalities and environmental policy," Journal of Public Economics, 69, 1-16.

[2] Barrett, S. (1994), "Strategic environmental policy and international trade," Journal of Public Economics, 54, 325-338.

[3] Fredriksson, P.G. and Gaston, N. (2000), "Environmental governance in federal systems: the effects of capital competition and lobby groups," Economic Inquiry, 38(3), 501-14.

[4] Fredriksson, P. G., M. Mani, and J.R. Wollscheid (2006), "Environmental federalism: a panacea or Pandora's Box for developing countries?," World Bank Policy Research Working Paper 3847. 
[5] Holtz-Eakin, Douglas and Thomas Selden (1995), "Stoking the fires? CO2 emissions and economic growth," Journal of Public Economics, 57, 85-101.

[6] Horn, H., G. Maggi, and R.W. Staiger (2007), "Trade agreements as endogenously incomplete contracts," CEPR Discussion Paper No. 6037.

[7] Kunce, M. and J. Shogren (2002), "On environmental federalism and direct emission control," Journal of Urban Economics, 51, 238-245.

[8] Kunce, M. and J. Shogren (2005), "On interjurisdictional competition and environmental federalism," Journal of Environmental Economics and Management, 50, 212-224.

[9] Levinson, A. (1997), "A note on environmental federalism: interpreting some contradictory results," Journal of Environmental Economics and Management, 33, 359-366.

[10] List, J. and S. Gerking (2000), "Regulatory federalism and environmental protection in the United States, Journal of Regional Science, 40(3), 453-471.

[11] Markusen, J., E. Morey, and N. Olewiler (1995), "Noncooperative equilibria in regional environmental policies when plant locations are endogenous," Journal of Public Economics, 56, 55-77.

[12] Millimet, D. (2003), "Assessing the empirical impact of environmental federalism," Journal of Regional Science, 43(4), 711-733.

[13] Murdoch, J., and T. Sandler (1997), "The voluntary provision of a pure public good: the case of reduced CFC emissions and the Montreal Protocol," Journal of Public Economics, 63, 331-50.

[14] Oates, W.E. and R. M. Schwab (1988), "Economic competition among jurisdictions: efficiency enhancing or distortion inducing?," Journal of Public Economics, 35, 333-354.

[15] Peltzman, S. and T. N. Tideman (1972), "Local versus national pollution control: Note," American Economic Review, 62, 959-963.

[16] Richter, W. and D. Wellisch (1996), "The provision of local public goods and factors in the presence of firm and household mobility," Journal of Public Economics, 60, 73-93.

[17] Sigman, H. (2005), "Transboundary spillovers and decentralization of environmental policies," Journal of Environmental Economics and Management, 50, 82-101. 
[18] Ulph, A. (1999), "Harmonization and optimal environmental policy in a federal system with asymmetric information," Journal of Environmental Economics and Management, 39, 224-241.

[19] Wellisch, D. (1995) "Locational choices of firms and decentralized environmental policy with various instruments," Journal of Urban Economics, 37, 290-310.

[20] World Bank (2008). The Little Green Data Book 2008. (Washington, DC: International Bank for Reconstruction and Development/The World Bank). 